\title{
Jeanne Calment's Unique 122-Year Life Span: Facts and Factors; Longevity History in Her Genealogical Tree
}

\author{
François Robin-Champigneul
}

\begin{abstract}
Jeanne Calment's (JC) still unmatched validated human life span of 122 years and 164 days, over 3 years longer than any other, surprises many. While her case is broadly accepted as a golden standard of validation, her record age still raises skepticism among some. The probability of such a record to be achieved by someone born in the second half of the 19th century, in the world population documentarily eligible to age validation, and also in the G7 countries, can be calculated by applying some logistic and Gompertz mortality models to these populations, taken, respectively, from the age of 117 and of 100. This probability appears substantial, respectively, $7.1 \%$ and $4.7 \%$, when using a four-parameter logistic model, which I validated on the observed survivals of centenarians until the age of 118. A 3-year interval with the second oldest is then expected. The known facts and documents constitute consistent evidence that JC died at 122: regular official records during her life, her verified memories from her 19th century life, her usage of specialized terms and of an abbreviation system specific to this period of time, photographs, her signature and handwriting, testimonies from numerous witnesses of her life, plus the expertise of gerontologists. Meanwhile, nothing contradicts her record: the daughter/mother identity swap hypothesis appears unrealistic and not supported by any evidence; especially no plausible motive can be found, on the contrary. The latest article, which defends this hypothesis, "Bayesian assessment of the longevity of JC,' contains major errors, making its result subjective and invalid. The study of JC's genealogical tree on six generations, using longevity performance and total immediate ancestor longevity indicators, shows how, in two centuries, her ancestors have been living $10 \%$ longer on average at each generation, increasingly overperforming their French 25-year-old contemporaries, from around $7 \%$ in the early 18th century to $43 \%$ for her parents, and up to $56 \%$ for her older brother and $80 \%$ for herself, which suggests a progressive concentration of longevity factors. In addition to the hereditary factors, JC's personal overperformance suggests also some environmental factors, and indeed many are known. Further knowledge could be obtained by studying JC's existing blood and DNA samples: those could not only provide an additional proof of her authenticity, but more importantly could be of immense contribution for understanding deeper the factors and patterns of her longevity, and more generally the longevity and aging processes in humans in general as well.
\end{abstract}

Keywords: Jeanne Calment, oldest human, longevity performance, supercentenarians, validation, mortality trajectory, logistic model, genealogical tree

\section{Introduction}

$\mathbf{J}$ EANne Calment's (JC) record longevity of 123 Spring seasons, dying in 1997 at 122 years and 164 days, is striking, more than 3 years longer than the second-longest validated longevity (the American Sarah Knauss, who died at 119 years and 97 days in 1999).
Initially regarded with skepticism in the scientific community, her case has been extensively validated while still alive, thanks to the initiative from Dr. Michel Allard and Jean-Marie Robine, who, with Dr. Victor Lèbre, conducted dozens of interviews of her, and, with the archivist Caroline Bisson (Boyer), performed a large documentary research and verification. This 2-year long work was detailed in a book

Independent scholar, Paris, France. 
published in $1994 .^{1}$ Then, on the day after JC's 120th birthday, an informal international committee formed by the American demographer James W. Vaupel, the Finnish demographer Väinö Kannisto, and the Danish epidemiologist Bernard Jeune visited her and verified the documents of her validation. $^{2}$

JC (Fig. 1) was the first documented supercentenarian to reach the age of 115 and verified by researchers independent from the Guinness World Records. ${ }^{2}$ As of today, she remains the only validated supercentenarian who crossed a symbolic threshold once considered a limit of human life span, the 120th anniversary, becoming what could be called the first verified "hypercentenarian."

Even after her validation, this exception continued to surprise but also to raise skepticism among some, for instance, Leonid Gavrilov and Natalia Gavrilova. ${ }^{3}$ Her case seemed to be in contradiction with the broadly used Gompertz models of mortality, as noted by Nicolas Brouard. ${ }^{4}$ Some even recently suggested that it would be more likely that she swapped her identity with her daughter Yvonne than having reached the age of $122,{ }^{5}$ although no case of such identity swap (which is far beyond just identity usurpation) has ever been recorded either, at least in France, since the modern Civil registration was established in 1792.

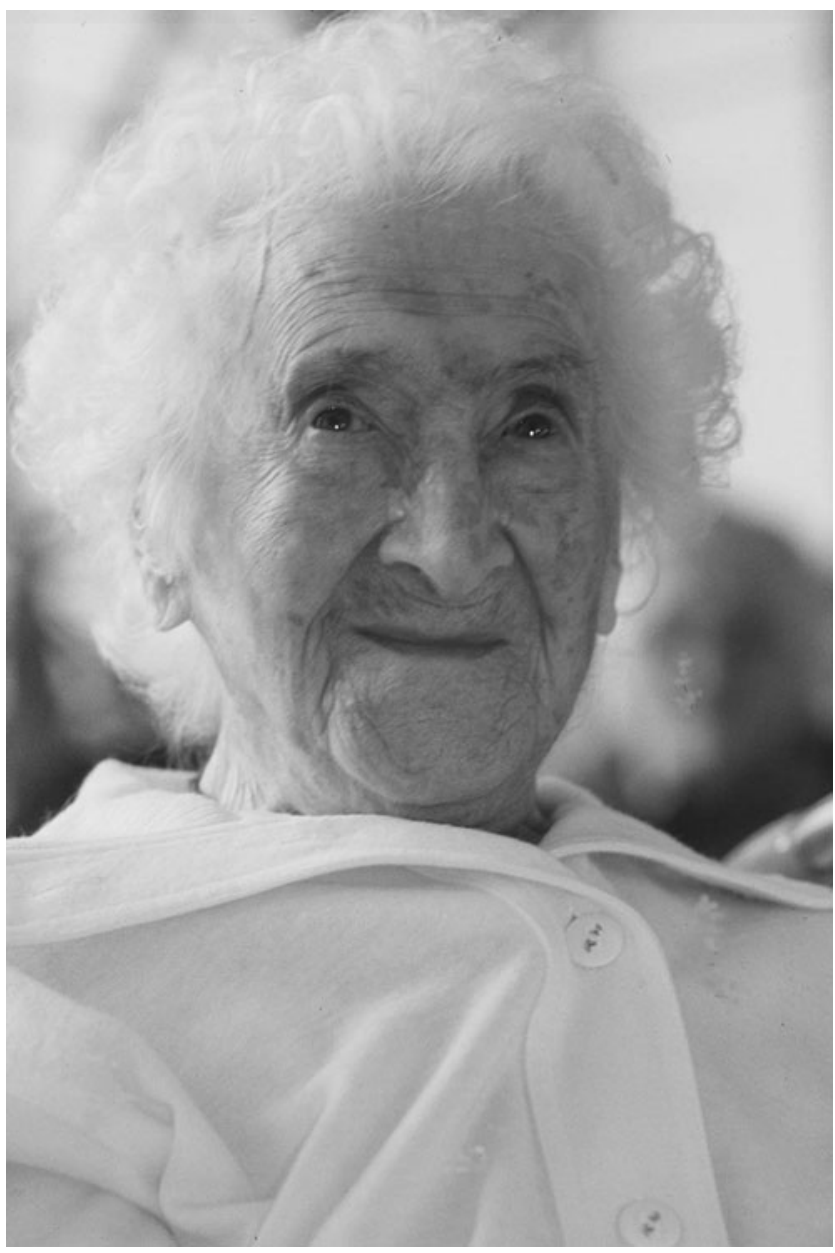

FIG. 1. Jeanne Calment at 117 (February 1992). Photograph published with permission from Tschaem/Sipa Press.
It is therefore useful to examine, thanks to the additional data accumulated on (super)centenarians in the recent years, how likely her case was to appear or not, to review the facts that support her exceptional longevity and whether the allegations of a possible identity swap are supported by any evidence. After this, we examine to which extent her heredity could explain such a record through the study of her ancestry and see if some environmental factors may have played a role too. Then, we see briefly how her cells and DNA may include some precious information about the mechanisms and genes involved in aging and longevity, and how the existing samples could be authenticated.

\section{Facts Supporting That JC Lived 122 Years}

\section{Possibility and reasonability of such a life span}

Centenarian's population and mortality models. According to the Human Mortality Database, ${ }^{6}$ there have been about $567,000 *$ new centenarians in the G7 countries from 1950 till 2000, including 52,725 (9.3\%) in France. These centenarians were potentially able to reach the age of 122 between 1972 and 2022. In fact, according to the records of validated supercentenarians, who are mostly from the G7 countries, ${ }^{\dagger}$ only one, ${ }^{\dagger} \mathrm{JC}$, did reach such an age. Was this likely to happen?

To answer precisely this question, we need a mortality risk mathematical model valid for the supercentenarians. Robine et al. ${ }^{8}$ have recently proposed such models, based on the French 1875 and 1903 birth cohorts' data: for each cohort they calculated a logistic and a Gompertz fourparameter model, which we note L-1875, L-1903, G-1875, and G-1903. I'm adding an additional logistic model, noted $\mathrm{L}-\mathrm{Avg}$, the parameters of which are defined as the average of the L-1875 and L-1903 models' parameters. The formulas and parameters of the models are given in Appendix A1.

These models can be compared with the International Database on Longevity (IDL) data $^{9}$ for the cohort of the French individuals born between 1881 and 1903, which are high-quality data since they seem to be exhaustive for these years, and since this data set was directly extracted from the French National Directory for the Identification of Physical Persons (RNIPP) and was validated by the French National Institute of Health and Medical Research (Inserm). This comparison shows that the L-Avg model is the model that fits the data the best, but the L-1903, G-1903, and L-1875 models fit well also (Figs. 2 and 3 ). ${ }^{\S}$

It can be noted from Figure 2 that it would have been expected to have one French centenarian surviving to 116 years in this cohort, although this did not happen (however, extending the time interval down to 1875 would add such a

*566,946 distributed as follows: USA 319,700, GBR 53,512, FRA 52,725, JPN 46,823, DEU 35,170 (Germany's data are not available for 1951-1955 so that I extrapolated an average of 40 new centenarians per year in these 5 years), ITA 32,304, CAN 26,711. These figures are the sum of the 100-year olds at January 1, from 1851 to 1901 included.

$87.9 \%$ of the supercentenarians (1528/1739) from the January 2015 database of the GRG were born in the G7 countries. ${ }^{7}$

A All of these centenarians are already deceased in 2019.

${ }^{\S}$ The determination coefficients represented in Figure 2 are for all points except the age 115, which has been excluded as it contains only one individual. 


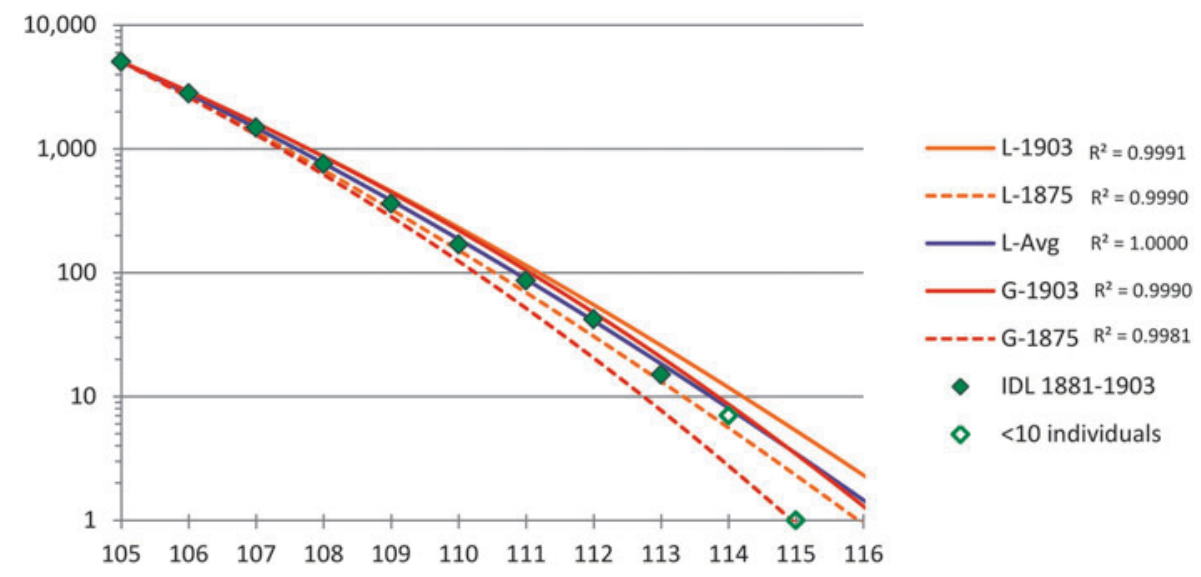

FIG. 2. Survivors per age from the French 1881-1903 birth cohort.

centenarian, with JC; unfortunately, the IDL data before the 1881 year of birth are too partial for doing such a study with the same data quality).

The comparison with the larger cohort of individuals born between 1850 and 1900 in the G7 countries allows validating further the models with some older ages. This cohort counts:

Six supercentenarians who died at the age of 117 or over (JC, Sarah Knauss, Marie-Louise Meilleur, Emma Morano, Misao Okawa, and Nabi Tajima. $\left.{ }^{* *}\right) .8,10,11$

Thirteen who died at age 116 or older (the same plus Susannah Mushatt Jones, Gertrude Weaver, Tane Ikai, Elizabeth Bolden, Besse Cooper, Jiroemon Kimura, and Jeralean Talley). ${ }^{7,11}$

We calculate the expected values for the number of survivors at 116 and 117, depending on the model, in the G7 population of about 567,000 centenarians born between 1850 and 1900 (Table $1^{\dagger \dagger}$ ).

More generally, these survivals can be represented on a graph (Fig. 4).

The models L-Avg and G-1903 fit remarkably well with the observed data for this cohort at the ages 116 and 117. However, at ages lower than 113, which are ages where the observed data are statistically the most significant because of the larger populations observed, we see here, such as before on the French data, that the L-Avg model fits much better.

At 118 , the observed data are still perfectly aligned with the model. Beyond this age, it can be seen as the result of a heads or tails game with two participants: Sarah Knauss won once and then lost, while JC was luckier and won four times before losing. If either JC or Sarah Knauss would have died at 118 (i.e., just 98 days earlier for Knauss), the data would even have fit perfectly on the model's curve at 119 .

\footnotetext{
**Nabi Tajima's case is, however, not yet fully validated.

${ }^{\dagger}$ Observed survivors at 111: the GRG database from January 1 , $2015,{ }^{7}$ and the GRG database "recent deaths 2008 to present,", 11 when merged (and with Lucy Hannah removed), count 715 validated individuals, born in 1850-1900, who died at 111+ in the G7 countries. However, this is an undercount because the cases for the ages 110-111 are known to be underreported in Japan as some Japanese prefectures did not report the ages 110-111, at least until recently, ${ }^{12}$ and according to the per country survival curves they might be underreported also in Canada.
}

As a conclusion, we have a model, L-Avg, which represents well the mortality rates till the age 118 for people born in the second half of the 19th century. We below extrapolate to the older ages to evaluate the probabilities for having a 122-year longevity record such as the one from JC, and we keep also the G-1903 model for comparison.

Limit of human longevity. First, to better understand these models, let us extrapolate to the limit of human life.

The four-parameter logistic models have got a mortality risk that converges to a maximum equal to the sum of their first two parameters $\left(b_{0}+b_{1}\right)$, which is here, respectively, $64.65 \%, 66.77 \%$, and $68.90 \%$ for the L-1903, L-Avg, and L-1875 models. This means that with such models there is no absolute limit for human longevity. However, some statistical limits can be defined. For instance, if one would define the limit of human longevity as the age that less than 1 per 1 billion centenarians would reach, this statistical limit would be 128,127 , and 126 years, respectively, for these models.

With the four-parameter Gompertz model (as given in Appendix A1), the mortality risk continues to increase with age until it reaches $100 \%$, at an age that is then an absolute limit for longevity (the function also converges toward $b_{0}+b_{1}$, but this sum is superior to 1$)$. In the G-1903 model, this absolute limit is 144 years, while its statistical limit under the definition given above is 125 years. This model is, however, not exactly the original Gompertz model but an approximation. The exact Gompertz model is defined by an exponential mortality force that tends to the infinite, so that the mortality risk tends to 1 but never reaches this limit, which means that the model does not give any absolute limit for human life. ${ }^{13}$

The fact to have a mortality risk that stabilizes toward a limit, such as in the logistic mortality models, could be intuitively explained with the notion of biological age if we suppose that, at the most extreme ages, the main reason why people live longer is that they have been able to benefit, thanks to some favorable factors, from a slower aging process. Thus, at such an extreme age, a person living longer than others would still have almost the same biological age as a random person who will die 1 year younger, since the longer lived would simply have aged slower. Therefore, this person would have almost the same mortality risk. This 


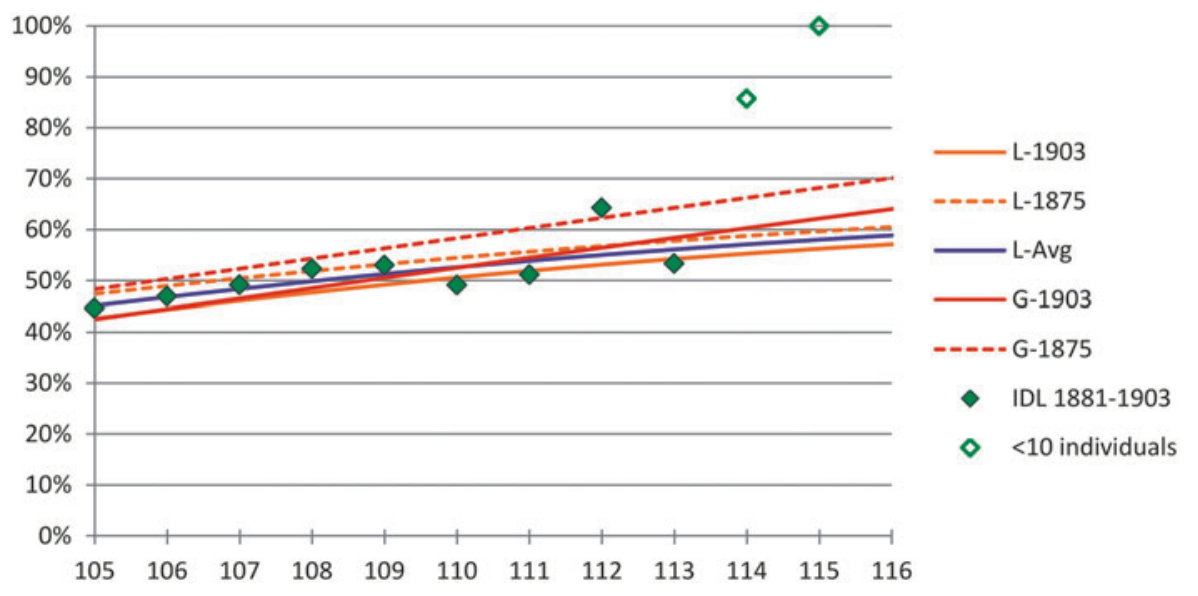

FIG. 3. Mortality risk per age for the French 1881-1903 birth cohort.

phenomenon of mortality risk convergence at the oldest ages is what is called the mortality plateau.

Alternatively, a model such as the Gompertz used here, with a mortality risk exponentially raising up to $100 \%$, could be intuitively explained with a limited plasticity of the aging pace, meaning some limited possibilities of slowing it down, no matter how good the environmental and genetic factors are. If any human would reach the maximum age allowed by these limited possibilities, then this human would not be able to survive any longer (or would have almost no chance to survive any longer, with the nonapproximated Gompertz defined for the mortality force instead of mortality risk).

JC's longevity probability among G7 centenarians or among validated 117-year olds. Let us consider the following two cohorts, representative of the population from which an oldest validated human could be recorded:

1. The centenarians of the G7 countries born between 1850 and 1900, for which we have already seen that it counted about 567,000 centenarians.

2. The worldwide validated supercentenarians who reached the age of 117 (at least), born between 1850 and 1901 . We observe eight such validated supercentenarians (the ones mentioned above, plus Violet Brown, from Jamaica, and Chiyo Miyako, born in 1901 in Japan ${ }^{7,11}$; if we would extend the birth interval to 1903, there would be a ninth one with Kane Tanaka, but she is still alive and only extinct cohorts are considered here).

For these cohorts, we can calculate various survival probabilities and ratios to understand to which extent some cases such as JC (122) and/or Sarah Knauss (119) were likely to be observed (Table 2), using the best data-fitted model L-Avg and also the more pessimistic, more poorly fitting data, but still data-compatible, model G-1903.

If each centenarian is considered individually, his or her probability for reaching or exceeding 122 years is 1 to 12 million with the L-Avg model and 1 to 40 million with the G-1903 model.

However, when considering the whole "validated 117+" or "G7 centenarian" cohorts, it appears that an age record such as JC's (122+), although not the most likely, had substantial chances to occur, respectively, $7.1 \%$ and $4.7 \%$ in these cohorts with the L-Avg model. Even with the more pessimistic model G-1903, such a record had reasonable chances to be observed in both cohorts $(2.1 \%$ and $1.4 \%)$.

It has been argued that the 3-year and 67-day gap between JC and Sarah Knauss was surprising and casting doubts on the record (e.g., Brouard $\left.{ }^{14}\right)$. However, this gap is exactly what would have been expected in the case where the oldest one would reach 122, so the fact that the second one is so far behind does not make the 122 record less likely. In such a case, the probability for having a 3- to 4-year gap is, respectively, $65 \%$ for the $117+$ cohort and $63 \%$ for the $\mathrm{G} 7$ cohort with L-Avg model (even more with the other model). In the $117+$ cohort, the most likely age for the dauphine of JC is 119 years, exactly what is observed with Sarah Knauss.

In fact, observing outliers in such a population is absolutely normal and statistically expected, so much so that not observing outliers could be in fact more unlikely. Having a record such as JC's is 4.4 times more likely than not observing any $118+$ survivors in the $117+$ cohort, and $40 \%$ as likely in the G7 centenarian cohort (with the L-Avg model; while with the G1903 model, it is, on the contrary, less likely).

Even observing the specific configuration " 122 and 119" is 1.6 more likely in the $117+$ cohort than not observing any $118+$ (again, it is, however, not the case with the Gompertz

Table 1. Survivors in the G7 1850-1900 Birth Cohort, Observed and Model-Expected Values

\begin{tabular}{lccccrr}
\hline Survivors per age & Observed & $L-1903$ & $L-1875$ & $L-A v g$ & $G-1903$ & $G-1875$ \\
\hline 100 & $(566,946)$ & 566,946 & 566,946 & 566,946 & 566,946 & 566,946 \\
111 & $>715$ & 1269.11 & 490.58 & 782.48 & 1200.71 & 362.95 \\
116 & 13 & 25.63 & 6.60 & 12.85 & 14.89 & 2.08 \\
117 & 6 & 11.00 & 2.61 & 5.28 & 5.35 & 0.62 \\
\hline
\end{tabular}

Italics indicate HMD data (which is established from censuses with interpolation techniques), used as the starting point for the survival calculus in the higher ages. 


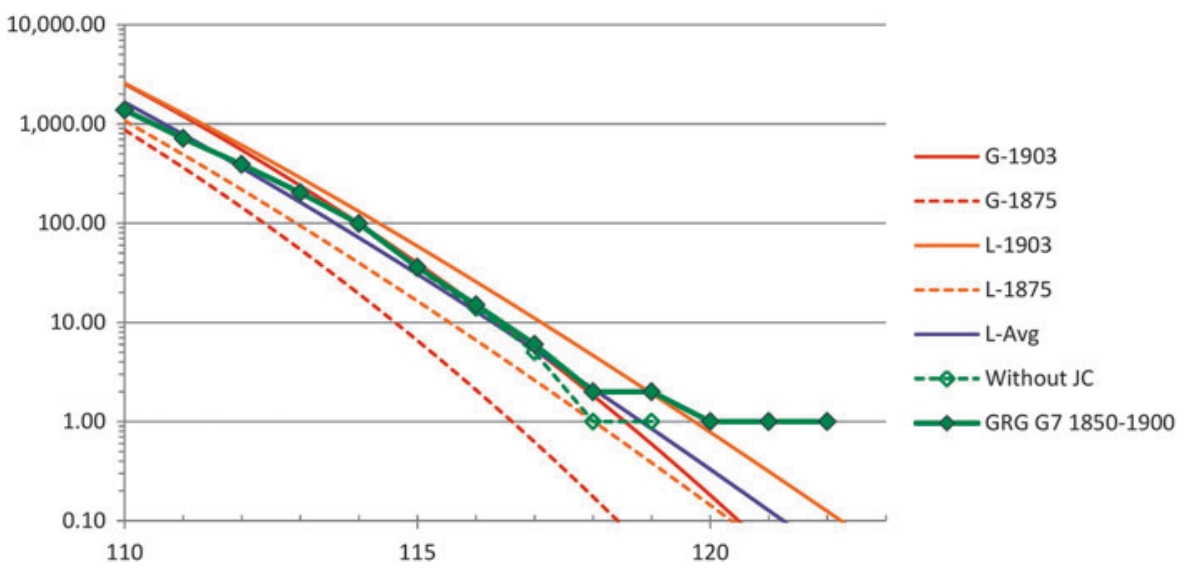

FIG. 4. Survivors per age for the G7 countries 1850-1900 birth cohort.

model). In other words, if JC and Sarah Knauss would not have lived over 117, which means that no centenarian would have lived older than 117 years, this situation would have been statistically more unlikely than their observed longevity of 119 and 122 .
As for Sarah Knauss's age, observing in these cohorts at least one $119+$ survivor is 47.1 times and 4.8 times more likely than not observing any $118+$ survivor, with the L-Avg model, and still 17.2 and 2.8 times more likely with the G-1903 model.

Table 2. Survival Probabilities in the G7 Centenarians and World-Validated 117+ Cohorts

\begin{tabular}{|c|c|c|c|c|c|}
\hline \multirow{2}{*}{$\frac{\text { Cohort }}{\text { Mortality model }}$} & & \multicolumn{2}{|c|}{$\begin{array}{l}\text { G7 centenarians } \\
\text { born } 1850-1900\end{array}$} & \multicolumn{2}{|c|}{$\begin{array}{l}\text { World-validated 117+ } \\
\quad \text { born 1875-1901 }\end{array}$} \\
\hline & & $L-A v g$ & $G-1903$ & $L-A v g$ & $G-1903$ \\
\hline \multirow{3}{*}{\multicolumn{2}{|c|}{$\begin{array}{l}100+\text { survivors } \\
117+\text { survivors (expected or known value) } \\
\text { Probabilities that }\end{array}$}} & 566,946 & 566,946 & & \\
\hline & & 5.28 & 5.35 & 8 & 8 \\
\hline & & & & & \\
\hline \multirow{13}{*}{$\begin{array}{l}\text { (a) A random individual reaches } 122 \\
\text { (b) The oldest one dies at }\end{array}$} & & 8.5E-08 & $2.5 \mathrm{E}-08$ & $0.91 \%$ & $0.27 \%$ \\
\hline & 115 & $0.00 \%$ & $0.00 \%$ & & \\
\hline & 116 & $0.51 \%$ & $0.47 \%$ & & \\
\hline & 117 & $11.34 \%$ & $15.59 \%$ & $1.60 \%$ & $3.54 \%$ \\
\hline & 118 & $31.06 \%$ & $39.27 \%$ & $23.16 \%$ & $35.65 \%$ \\
\hline & 119 & $28.97 \%$ & $28.10 \%$ & $34.92 \%$ & $36.75 \%$ \\
\hline & 120 & $16.20 \%$ & $11.47 \%$ & $22.64 \%$ & $16.51 \%$ \\
\hline & 121 & $7.22 \%$ & $3.68 \%$ & $10.62 \%$ & $5.45 \%$ \\
\hline & 122 & $2.91 \%$ & $1.05 \%$ & $4.36 \%$ & $1.56 \%$ \\
\hline & 123 & $1.12 \%$ & $0.28 \%$ & $1.69 \%$ & $0.41 \%$ \\
\hline & 124 & $0.42 \%$ & $0.07 \%$ & $0.64 \%$ & $0.10 \%$ \\
\hline & (c) $119+$ & $57.09 \%$ & $44.66 \%$ & $75.24 \%$ & $60.81 \%$ \\
\hline & (d) $122+$ & $4.70 \%$ & $1.41 \%$ & $7.05 \%$ & $2.11 \%$ \\
\hline \multirow{6}{*}{$\begin{array}{l}\text { (e) Exactly one reaches } 122 \\
\text { (f) In such case, the second oldest dies at }\end{array}$} & & $4.58 \%$ & $1.40 \%$ & $6.83 \%$ & $2.09 \%$ \\
\hline & 117 & $11.90 \%$ & $15.81 \%$ & $2.86 \%$ & $5.47 \%$ \\
\hline & 118 & $32.59 \%$ & $39.84 \%$ & $28.57 \%$ & $39.42 \%$ \\
\hline & 119 & $30.40 \%$ & $28.50 \%$ & $36.44 \%$ & $35.19 \%$ \\
\hline & 120 & $17.00 \%$ & $11.63 \%$ & $22.06 \%$ & $15.04 \%$ \\
\hline & 121 & $7.58 \%$ & $3.74 \%$ & $10.07 \%$ & $4.88 \%$ \\
\hline \multicolumn{2}{|c|}{$\begin{array}{l}\text { (g) The oldest one reaches } 122 \text { and the second oldest dies } \\
\text { at } 119\end{array}$} & $1.39 \%$ & $0.40 \%$ & $2.49 \%$ & $0.73 \%$ \\
\hline \multicolumn{2}{|c|}{ (h) None of them reaches 118} & $11.84 \%$ & $16.06 \%$ & $1.60 \%$ & $3.54 \%$ \\
\hline \multicolumn{2}{|l|}{ (i) None of them reaches 120} & $71.88 \%$ & $83.44 \%$ & $59.68 \%$ & $75.94 \%$ \\
\hline \multicolumn{2}{|l|}{ Ratio (d)/(h) } & 0.40 & 0.09 & 4.41 & 0.60 \\
\hline \multicolumn{2}{|l|}{ Ratio (g)/(h) } & 0.12 & 0.02 & 1.56 & 0.21 \\
\hline \multicolumn{2}{|l|}{ Ratio (c)/(h) } & 4.82 & 2.78 & 47.06 & 17.20 \\
\hline \multicolumn{2}{|l|}{ Ratio (d)/(i) } & 0.07 & 0.02 & 0.12 & 0.03 \\
\hline
\end{tabular}

Italic indicates initial populations used for the survival calculus.

Bold indicates main figures discussed in the text.

Light gray indicates the probability of having an age record such as JC's in the cohort. 
To summarize, according to the model (L-Avg), which fits the best with the observed mortalities between 105 and 117 , the most likely age for the record, given the observed number of validated $117+$ survivors, would be between 118 and 120 (80.7\% probability); however, a record at $122+$ had still substantial chances to be observed $(7.1 \%)$, and even the specific observed configuration of a record at 122 and a second one at 119 is a statistically very reasonable case, which had a probability of $2.5 \%$ to be observed, more than some other configurations, for instance, more likely than the absence of $118+$ survivors.

With regard to the JC's authenticity-skeptical studies, Zak and Gibbs ${ }^{5}$ have calculated a probability ratio of 1 to 2 million between the survival to 122 and the survival to 99 , of two French women, respectively, 59 and 36 years old in 1934 (Jeanne and Yvonne Calment were, respectively, 58 and 36 years old when Yvonne died in 1934), using mortality rates that they consider to represent the most accurately the mortality of the Calment family. This ratio is comparable, and even more favorable, with the ratios of 1 to 12 million and 1 to 40 million which I calculated with the L-Avg and G-1903 mortality models. This Zak/Gibbs result is therefore in fact also in line with the results presented above.

\section{Positive facts about JC}

Regular track records of JC during all her life span. JC has been recorded with her age at regular intervals in all 17 censuses in Arles from the age of 1 till 100. ${ }^{8}$ She appears also in a dozen civil registration acts, starting with her birth record on February 22, 1875 (born on the day before), and in various parish acts and notary acts throughout her life. ${ }^{15,16}$ The mayor of Arles met her in 1975 for her 100th birthday. ${ }^{17}$ In a letter from August 1977 to her grandson's sisterin-law, she mentions her age of 102 years and a half. ${ }^{18}$ Since the age of 110 , she has been followed by the medical team of the retirement home and the journalists.

Verified correct memories about 19th century personal facts and acquaintances. JC from her retirement home could correctly recall facts and names from her early life in the 19th century, which even her daughter Yvonne, born in 1898 , would have been unlikely to know and remember for life.

Her memories, which could be verified as exact in the archives, include the following people and facts:

1. The death of the torero Espartero (1866-1896) in Nîmes from fatal injuries received in the arena, which she saw with her husband, and indeed the date, October 4,1896 , was a few months after their wedding. ${ }^{20}$

2. The tailor Ms. Chambourdon (1840-1898). $\$ \S 21$

3. The pension of Madame Benet (1853-1898) ${ }^{* * *}$ where she went to school, which existed only between 1880 and 1889 , when Mrs. Benet moved $40 \mathrm{~km}$ away from Arles. $^{21}$

\footnotetext{
\$Manuel Comeche Alcántara "Espartero" (Alcublas near Valencia, Spain, April 10, 1866-Nîmes, France, October 7, 1896). ${ }^{19}$

${ }^{\S \S}$ Angeline Henriette Chambourdon (Arles, February 22, 1840 Arles, June 18, 1898) never married. ${ }^{16}$

Marguerite Coste (Avignon, August 16, 1833-Port-SaintLouis-du-Rhône, February 4, 1898) married to Claude Benet on April 26, 1880, in Arles. ${ }^{16}$
}

4. Her teacher of physical sciences Mr. du Bourguet (1853-1907), ${ }^{\dagger \dagger \dagger}$ who was not from Arles but Marseille, where his wife has always stayed, but who taught in Arles from 1886 to 1894 , precisely when JC was at the age for studying this subject. ${ }^{21}$

5. The piano teacher Césarie Gachon (born in 1867), her parents (who died in 1898 and 1900), their bakery (which became Mr. Meyrieux's bakery in 1892 when the Gachon's retired), and the location of the Gachon's home “behind" their bakery. $§ \S \S 21,23$

6. The name of her godfather Louis Paget (18101897).

7. The address of her godfather almost correctly, since she said "rue du Théâtre" (Theater street) while he was living in "rue des Arènes," the "arènes" being the Roman amphitheater. ${ }^{23}$

8. The name of her godmother Jeanne Gilles.

9. The midwife Mrs. Nevière (1840-1907) ${ }^{\dagger \dagger \dagger \dagger}$ and the fact that she assisted both for Jeanne's birth in 1875 and for Yvonne's birth in $1898 .^{21}$

10. The name and occupation of her grandfather Claude Gilles (1816-1898) who was a miller, and she answered the question about "[her] grandfather" without any hesitation and spontaneously talked about her maternal grandfather instead of her paternal grandfather, which is logical since her paternal grandfather died in 1871 before her birth so that she personally knew only the maternal one who died in 1898.

These memories from JC can be found in the interviews performed by Allard, Robine, and Lèbre ${ }^{24}$ (items 1-9), in Lamy ${ }^{17}$ (additional details on item 5) and in a filmed interview by Dr. Lèbre ${ }^{25}$ (item 10). Most of the elements from this list were already published in August 2019 in a comment written by Mélanie Perny-Villeneuve and myself on PLoS Biology. ${ }^{26}$

Even if it happened, however rarely, that she confused some other memories, like anyone normally does sometimes especially at an old age, no one else than JC was likely to know and remember in old age all these names and details from her early life.

About JC's interviews, the extracts that may seem to support the identity swap hypothesis should of course be considered too for an objective analysis. The most troubling one, by far, noted by Nikolay Zak, ${ }^{27}$ is when JC answered the question about the name of the servant taking her to school with a name, Marthe Touchon, who was apparently in fact Marthe Fousson (18851947), the servant who was employed by JC for a few years, at least between 1906 and 1911, when she could take Yvonne to school. At first glance this seems troubling; however, such a confusion in memories is something that people often do,

\footnotetext{
${ }^{\dagger \dagger}$ Horace Saint Prix Lucien d'Audibert Caille du Bourguet (Marseille, January 3, 1853-Marseille, March 26, 1907) married in Marseille on April 4, 1888 . $^{16}$

HACésarie Gachon born in Arles on December 21, 1867, to Jacques Gachon and Marthe Sanguin who died, respectively, in Arles on February 21, 1898, and October 27, 1900. ${ }^{16}$

${ }^{\S \S \delta}$ This memory was first verified in the archives by François Hureau. ${ }^{22}$

"Pierre Gilles "Louis" Paget (Arles, October 7, 1810-Arles, March 27, 1897) never married. ${ }^{9}$

†† Thérèse Joséphine Gouirand (Arles, March 29, 1840-Aix-enProvence, April 18, 1907) married to Guillaume Nevière on November 13, 1861, in Arles. ${ }^{16}$
} 
especially old people, and it should be noted that, in French families, servants were called by their first names and the children almost always ignored their last names, so that while Jeanne had to know the last name of her employee, Yvonne was much less likely to know this servant's last name, who got married in 1912 in Fontvieille (where she died in 1947) and probably left the Calment's at that moment.

JC made another confusion between events from both the mother's and daughter's lives, but in the opposite way. This is when, asked about the first communion of her daughter, she answered: "this was in a pension, a religious pension. The pension of Mrs. Benet, which was... I don't remember. At the moment I have a little amnesia, sometimes." However, the pension of Mrs. Benet existed only from 1880 to 1889 , so only Jeanne could have done her first communion there (which she also said she did in another interview). In this case, it seems rather unlikely that a daughter would forget her own childhood ceremony and remember instead what she may have been told about the mother's childhood. It seems more likely that a mother would confuse two similar events, which are both from her own direct memories: the moment when she assisted to her own first communion ceremony, probably the most intense one, and the one when she assisted to her daughter's ceremony. Seen from the 1990 s, events taking place in the 1900 s or 1880 s might both be seen as from a common very distant time, which may explain the occasional confusion.

She was using terms and abbreviations that her daughter was unlikely to know or use. JC, when talking about her father's boat construction activity, which he stopped when she was 8 years old after launching in 1883 a last boat called "Jeanne," was using some very specialized terms that only people familiar with this specific industry know:

"Mahonne"': this is a specific type of boat, precisely a port barge with rounded shapes. ${ }^{28}$

"Épontilles": in English "pen board," this is a stay used to keep a ship in dry dock on its keel. ${ }^{29}$

Her daughter was unlikely to know these terms and remember them in her old age.

In addition, for writing months, JC was using an abbreviation system typical from the 19th century and earlier centuries, which was normally not used anymore by the generation of her daughter. In her letter from December 29, 1983, to Mrs. Taque, she writes " $\mathrm{X}$ bre", for "décembre.,"30,* This abbreviation was still used in the Arles decennial tables in $1893,{ }^{31}$ but already not anymore in $1903,{ }^{32}$ which used "Déc bre", instead.

Documents (official acts, ID card, letters, tax return) bearing her signature and/or handwriting from 1896 till 1992 are graphically consistent, including a very specific rare pattern. JC's signature did not change from 1896 till 1992 apart from a few slow evolutions, mainly a progressive simplification. This is visibly the same handwriting during the whole period.

For instance, JC's handwriting and signature display one same very rare specificity at all periods of time: her hesitation about the way to draw a "J." Amazingly, she can

*This date does not exist; it was in reality either Thursday 29th or Friday 30th. draw this capital letter in two different ways within the same document, either with a simple loop or with a double loop (i.e., with an additional inflection point), as can be observed in the documents:

This is visible in a notary act from January 13, 1926 (under title "Constatation et acceptation d'emploi" about the usage made from some funds ${ }^{33}$ ), where JC writes her initials five times and then signs. Among her six " $J$ " in this document, three are done with a double loop and three with a single loop (one of them is drawn twice, superposed, as the first one was not properly shaped).

These two variants of the capital " $\mathrm{J}$ " are both present also on a 1957 JC's letter. ${ }^{34}$

Again, both variants appear simultaneously (superposed) on an envelope that she wrote in $1977 .{ }^{18}$

Her daughter was unlikely to notice this detail and be able to replicate the same hesitation in her writings lifelong.

Figure 5 shows some signatures, initials, and writing samples of JC from $1898,{ }^{35} 1900,{ }^{36} 1926,1930,{ }^{37} 1946,{ }^{38}$ 1957, and 1977, and the signature of her daughter Yvonne in $1926 .{ }^{39}$

Photographs of her are available at various ages that show the same woman. There are now about 20 photographs of JC before 1962 available, , , 17,22,40,41 and whatever the age, she always looks as the same person. In particular, her nose is very recognizable on all photographs, long and thin, with a discreet very tiny bump at about one-third from the top.

There are also more than a dozen photographs of her daughter Yvonne available, who looks sufficiently different for not confusing them one for another. This can be seen on the only photograph where they both appear together. In particular, Yvonne's nose is thicker and a little shorter, with a curve going slightly upward (especially visible when looking at the whole sets of photographs from each).

Some photographs have been occasionally misattributed. ${ }^{+1+}$ However, Jeanne and Yvonne look different enough for all these misattribution errors to have been detected by those who studied their photographs, and corrected rapidly and consensually. There is no debate anymore on who is who on the pre-934 photographs, because both women are recognizable enough one from another, even for people who know them only from these sets of photographs without having ever met them. People who knew them for real, such as their relatives and friends, would definitely not have confused them.

In addition, they had a 23-year difference, and the woman with salt-and-pepper hair, mostly white, seen on the 1937 , 1943, and 1945 photographs not only shows traits much

\footnotetext{
Notably the photograph of Yvonne alone in the Saint Trophime cloister, ${ }^{42}$ which has been mistakenly labeled for years "Jeanne Calment at 22" on Wikipedia and on the GRG website (Gerontology Research Group, which maintains a useful database of supercentenarians, with local correspondents worldwide who report, investigate, and validate cases) although it had been correctly published in $1988^{40}$ and $1995^{41}$ as Yvonne Calment (the error may come initially from a mix-up in the legends taken from the 1995 book, since this book had the same legend "Jeanne Calment at 22" but on another photograph two pages before). Nikolay Zak can be credited for noting and reporting, with Valery Novoselov, this error that has since then been corrected. ${ }^{43}$
} 


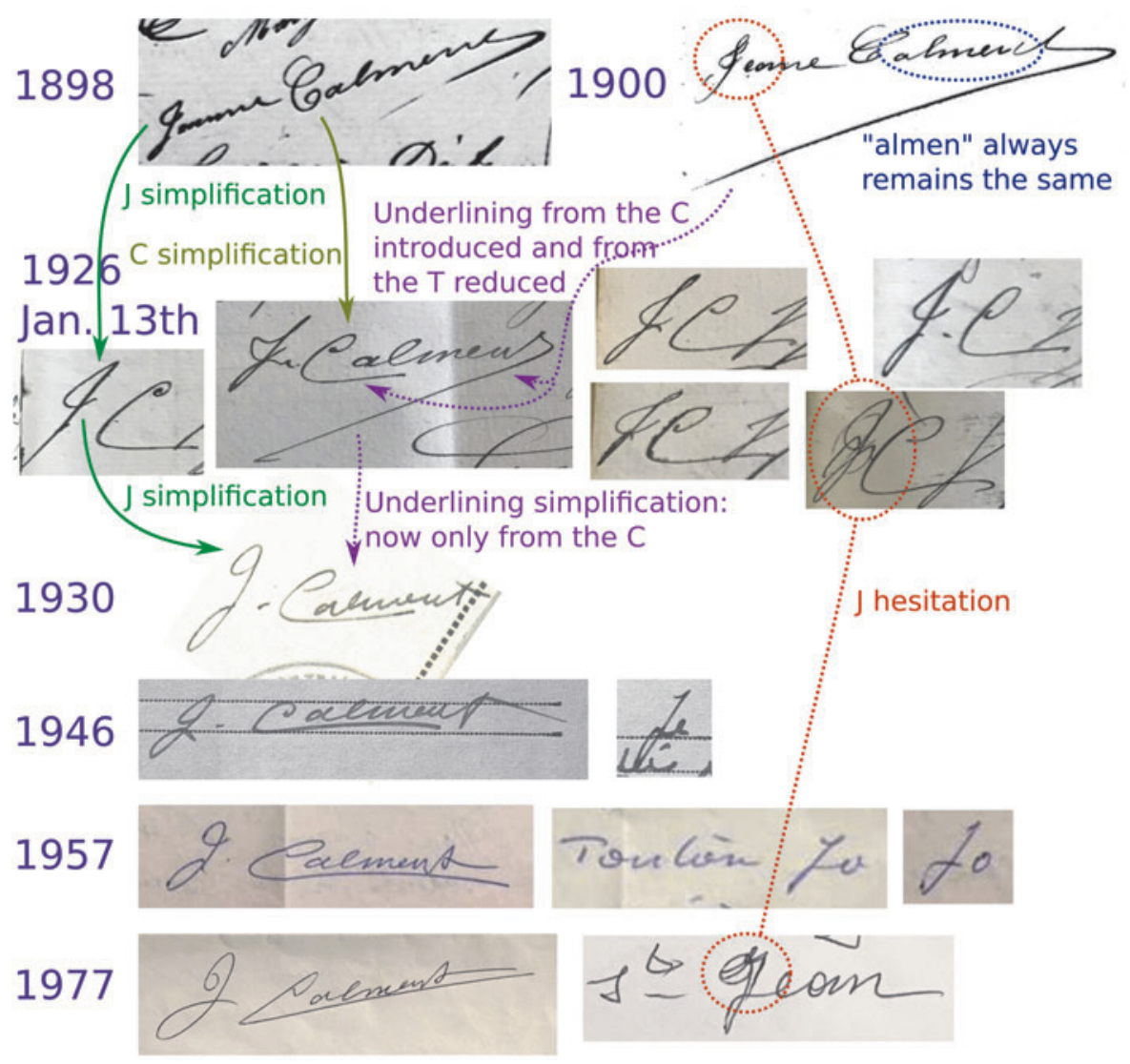

1926 Jan. 17th

Both Jeanne and Yvonne signatures together on Yvonne's wedding contract.

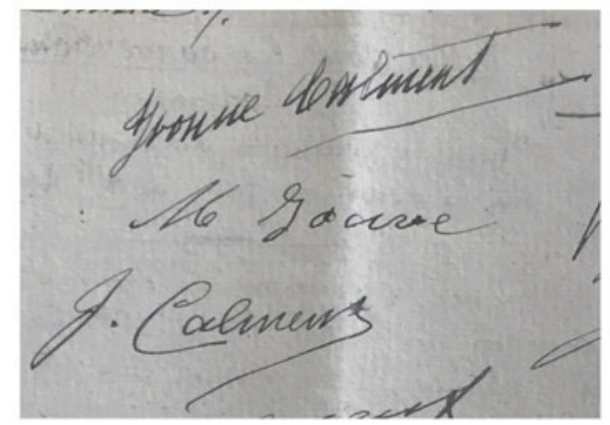

FIG. 5. Some signatures, initials, and writing samples of JC from 1898 to 1977.

more like the young Jeanne than like the young Yvonne, but also she looks like a woman in her 60 s, not like a woman in her late $30 \mathrm{~s} / \mathrm{mid}-40 \mathrm{~s}$ as would be Yvonne then.

There are dozens of witnesses of her life who could attest of her identity and would have detected if there had been a swap with her daughter. Jeanne and Yvonne Calment had a large family, mainly living in the same city of Arles, whose agglomeration counted 18,548 inhabitants in $1931 .{ }^{\S \S \S} \mathrm{A}$ "particularly large crowd" attended Yvonne's funerals in 1934 according to the local press. ${ }^{45}$ The death notification ("avis de décès") inviting people to the funerals was made

${ }^{\S \S \S \S}$ At the 1931 census (and 32,485 inhabitants for the whole municipality of Arles, which extends up to $40 \mathrm{~km}$ away from the agglomeration). ${ }^{44}$ [Note: JM Rouquette knew well Jeanne Calment since he was one of the two witnesses at the wedding of her grandson Freddy in 1950]. in the name of 40 close family members plus their children plus the employees of the Calment store, plus 13 more distant families, who invited everyone before the church ceremony to gather at the home of the deceased person where the French tradition was that the body could be seen just before being put in the coffin. ${ }^{46}$

The children from several second cousins of Yvonne have testified again in 2019 that JC's identity was authentic, including:

Geneviève Calment (1905-1995): her daughter Gilberte, who declared ${ }^{* * * * * *}$ that "the whole town knew that Yvonne was tubercular and that her mother was in good health." About the identity swap hypothesis, she said: "it's impossible; there was an age and beauty rivalry between my grandmother [Marie Joséphine Rousset, born

***** Translated from French by me. 
in 1878] and JC. If she had rejuvenated of 20 years, we would have seen it." And also: "my mother knew Jeanne young and older; if the person had changed, she would have seen it. It does not make sense.,"47-49

René Crouanson (1910-2001): his daughter Martine. ${ }^{22}$ Pierre Fassin (1912-2011), ${ }^{\dagger \dagger \dagger}$ president of the Academy of Arles: his daughter Claude. ${ }^{50}$

All of them also kindly provided photographs of Jeanne and/or Yvonne Calment.

Also, Claudie Taque, niece and goddaughter of Yvonne's son, has testified again that JC's identity was authentic, producing even some signed family letters from JC who was rejoicing about her good health despite her very old age (102 years and a half, she specifies in August 1977, certainly far from imagining that she still had 20 more years to live!). ${ }^{14,18}$

It is also known that some family members took care of JC for years such as Juliette Espeyte (1913-2016), ${ }^{51}$ a niece of Yvonne's husband, or Antoinette Billot (1902-2003), a sisterin-law of Yvonne and her daughter Josette Flauder (1927$2011),{ }^{52}$ who all never expressed any doubts about JC's identity.

So in the case of a supposed swap, would not all these people have been able to recognize their close relative Yvonne from her mother Jeanne? Or would they all have been accomplices of such a crime (an identity swap was not specifically mentioned in the French penal law but it would still imply a punishable criminal offense ${ }^{53}$ )? In either way, this is absolutely unrealistic.

There are also other testimonies, for instance, from Pierre Maxence (1926-2016), not a family member, who wrote in a testimony dated February 26, 1984, when JC was 109: "My father was employed by the Calment house (...). He has been working there for 27 years [till 1938]. Mrs. Calment, who is more than centenarian, is still alive." ${ }^{54} \mathrm{He}$ personally knew her, had been playing with her grandson Freddy when he was a child, knew also Yvonne, and wrote in another document: "The Calment family was a distinguished family from Arles. One could say a family of bourgeois with good manners, including the colonel Billot and his wife Yvonne Calment." 55

In addition, JC had servants at home. They would also have detected an identity swap since they remained in the position at the period of the supposed identity swap. For instance, Louise Gauzargues (born in 1894 in Arles) was JC's cook in 1931 and still in 1936, and Pauline Cheylan (born in 1895 in Arles) was a servant in 1931 and already in $1926 .^{23}$ They would have detected a swap if it would have happened, and later if a Yvonne faking to be Jeanne would still want to sometimes be herself (Yvonne) with her husband (official son-in-law) or with her father (official husband), she would have to switch identities at home, which would certainly soon get noticed by the servant(s).

All the doctors, including gerontologists, who examined her had no doubt about the authenticity of her age. JC has been examined by many gerontologists and none of them had any doubt about her authenticity. This includes Dr. Michel Allard and Jean-Marie Robine, who have met hundreds of

${ }^{\dagger+\dagger}$ For the wedding of Pierre Fassin in 1935, Yvonne's son, Freddy, wrote a beautiful letter accompanying the gift made by his family. centenarians (their detailed study about the French centenarians performed from 1990 to 2000 includes 800 centenarians whom they met ${ }^{56}$ ), Dr. Victor Lèbre who was an experienced doctor at the end of his career, ${ }^{24}$ and Dr. Georges Garoyan $^{57}$ and Dr. Catherine Levraud, ${ }^{14,24}$ who each wrote a lengthy medical thesis about JC. With their experience and expertise, and their personal examination of $\mathrm{JC}$, they all came to the same conclusion with certainty: her age is authentic. A nonagenarian woman, 23 years younger than said, would have been extremely unlikely to fool all these doctors who examined her and studied her case very thoroughly.

The nurses of the retirement home who saw her every day and have seen many other old people, including centenarians, had no doubt either; for instance, Claudine Serena who has been at the retirement home with JC for a dozen years. ${ }^{48,58}$

\section{Nothing contradicts her record}

No fact has been found, which contradicts her record. No fact has been found, which could contradict the authenticity of JC's identity. The scenario of an identity swap between JC and her daughter Yvonne has been reported by Allard and Robine in $2001^{56}$ and they explained that they could not find any motive for such a crime nor even the material possibility in the context of the Calment family where Yvonne Calment had a son, a husband, and a father alive, and the family was famous and socially prominent in Arles. They stated that "in order to substantiate this claim, a solid scenario should be put up, a genuine thriller, and this is not easy, if not impossible."

Nikolay Zak published in 2019 what he considered to be such a solid scenario. ${ }^{27}$ This gave a high visibility on this hypothesis and a positive consequence is that it motivated other people such as us to investigate further. The proposed scenario was certainly an attractive scenario from a Romanesque point of view, such as would be also a substitution by a Martian, however, when analyzed in details this interesting scenario appears to be not solid, not supported by any real facts, but rather illusions such as a nonexisting "fibroma."

Le Bourg ${ }^{59}$ and Robine et al. ${ }^{8}$ have already responded to most of the arguments that had initially been claimed in support of this theory.

The "alternative scenario" is not realistic. To understand how realistic the hypothesis of an ID swap between the mother and the daughter is, it can first be observed that:

No single example of any ID swap between a parent and his or her child has ever been found in France (not just a simple usurpation but also a swap, where each one dies with the identity of the other, as suggested in this scenario), although since the start of the French modern civil registration system in 1792, there have been more than 100 million people in France

Httin 1899 , there were in France 655,900 people of both sexes who became 18 years old. ${ }^{60}$ Their parents were approximately born 30 years before them, that is, in 1851 and, given the mortality tables, ${ }^{60}$ there was for each of them an $82.46 \%$ probability to be still alive in 1899 knowing that they were alive in 1881. This means that about 540,900 individuals became 18 in France in 1899 with their same-sex parent still alive. The same calculus can be made for each year from 1792 to 2019 . The sum is superior to 100 million persons. 
parent still alive when they became an adult, with whom they could therefore potentially have swapped identity, and although such a swap would likely be discovered, and if discovered would be sufficiently extraordinary for definitely being mentioned in the media.

Without any single known example, the baseline probability of such a swap is difficult to estimate but is likely less than 1 to 100 million.

So, to support such an unlikely swap, some serious evidence should be given. In the case of JC, this is, however, the opposite: not only no known fact or evidence suggests such a swap, not only the numerous witnesses make it virtually impossible to have happened without being noticed, but also Yvonne (and her supposed accomplice number one, Fernand) did not even have a motive, on the contrary, they had some strong motives against it.

A financial motive has been suggested with the idea that the inheritance tax rates were up to $40 \%$ in France in $1934{ }^{27}$ As already indicated, no example of an ID swap in France is known, be it for fiscal reason or whatever reason, but even if we suppose that a high rate of taxes could potentially be a motive for such a crime, I calculated, thanks to the detailed fiscal rates and laws of the time, ${ }^{61}$ that the average overall tax rate on inheritance in France in January 1934, in the case where a child and a spouse would be the heirs, would only be a s follows:

$6.23 \%$ or $6.41 \%$ (depending on whether a testament makes the husband inherit more than his minimum legal share or not) for a 250,000 francs asset,

and $6.61 \%$ or $8.17 \%$ for a 500,000 francs asset, which is more than the upper limit to which the assets of JC in 1934 can be estimated. $§ \S \S \S \S$

In addition, Jeanne's husband was richer than her as the Calment building and business came from his parents, ${ }^{62}$ and so, the amount of taxes to pay would have been very small compared with the wealth of the couple, probably in the order of $2 \%$, maximum $3 \%$. This is certainly not a possible motive for such a crime.

In fact, not only Yvonne Calment would not have had any motive for such a crime, but she, on the contrary, would have had strong motives for not committing such a crime, even if we suppose that such a strange idea would have come to her mind:

She had a 7-year-old boy. It would be unusually cruel for a mother to make him believe that his mother had died, and in any case unrealistic to make him confuse his mother with his grandmother. At the same time, it is also unrealistic to make such a young boy an accomplice of such a crime and keeping such a secret.

If Yvonne would become Jeanne, she would irrevocably lose all her parental rights on her child, leaving only her husband with such rights, who would be officially a widower and free to marry anyone.

\footnotetext{
$\S \S \S \S \S$ One way to get an idea of the value of JC's assets is to take the gross value of her assets in 1945 (1,047,775 francs), known from her tax return, ${ }^{38}$ and convert it according to the inflation rates into 1934 francs, which makes 190,505 francs (this figure includes her share from her husband's inheritance in 1942). It can also be more precisely estimated by establishing the detailed list of her assets and their value.
}

If Yvonne would become Jeanne, she would have to fake being the wife of her father, who was still alive, and fake not being the wife of her husband, such an insane and unpleasant situation for everyone.

If Yvonne would become Jeanne, she would have to stop being friends with her friends, and would have to fake being the friend of her mother's friends.

If Yvonne would become Jeanne, she would lose the 12,000 francs lifetime annuity that her parents had to pay her according to her wedding contract ${ }^{39}$ and, on the contrary, she would become the one in charge of paying it to Freddy (the benefit of the annuity was transferable to the children in case of death), and in practice her husband Joseph Billot would be the only one controlling the use of this money until the legal majority (21) of Freddy.

Everyone involved in the crime would take some very important penal and social risks, including the captain Billot, member of the Legion of Honor, and Fernand Calment, owner of the largest store in the very center of Arles, President of the Arles college alumni, ${ }^{63}$ Honorary President of the Arles Chorus "Orphéon d'Arles,",64 Vice-President of the hunting club "Société populaire des chasseurs gaulois",65 and recently (1931) awarded the golden palms distinction of Officer of the Public Instruction ("Officier de l'Instruction Publique"). ${ }^{63}$

Not to mention the risk for their soul, being a catholic family going to the church every day (at least JC was going to the church every day ${ }^{41}$ ).

For an unprecedented type of crime, would all these major problems and risks be taken without any extremely serious motive? This is perfectly unrealistic, like it is also unrealistic that nobody would discover the identity swap if it would happen.

On the contrary, the fact to live 122 years is realistic although with a very low probability. Events of the same nature have been observed at ages simply less old (by $2.6 \%^{* * * * * *}$ ) and for JC it is supported by all the known facts and testimonies as explained in previous paragraphs.

The "Bayesian analysis," which is supposed to show that an ID swap is more likely than the authenticity of JC, appears to be in fact a subjective and nonrigorous analysis. Zak and Gibbs have performed a "Bayesian analysis," which aims at showing that an ID swap between Jeanne and her daughter Yvonne is more likely than JC's authenticity, by comparing the probabilities of each of these two alternatives. ${ }^{5}$ The idea is interesting but unfortunately this analysis and its probability calculus contain three major errors:

1. What are considered in this analysis are not the two alternatives, but only three scenarios, subscenarios, within these two alternatives (one subscenario for the first alternative and two for the second alternative). Therefore, the probability of neither of the alternatives is calculated, which makes their comparison vain.

2. Their method is to choose a set of evidences and then to assign, in each of their scenarios and for each evidence, a conditional probability for the scenario to

The American Sarah Knauss (1880-1999) died at 119 years and 97 days, $2.6 \%$ less than JC. 
happen given the selected evidence. They obtain the probability of each scenario by multiplying these conditional probabilities. However, since they subjectively selected only a subset of evidences among all the evidences available, the probability calculus is therefore not exact. It is missing all the evidences that have been arbitrarily neglected.

3. The probabilities that they assign to each of the evidence are, in most cases, their own strongly subjective estimates.

Therefore, the subjectivity of the authors is very present in the choice of the subscenarios, including the only one where JC's record is authentic, in the choice of the selected evidence and in the probability estimates associated with this selection of evidence.

To illustrate the three errors mentioned above, here are some examples for each:

1. Only some subjectively chosen subscenarios are considered:

All scenarios assume that Yvonne had tuberculosis already in 1928 and has been recovering between 1929 and 1931. The probability of this double hypotheses, falsely presented as facts when they are mere hypotheses, is not evaluated, and nor are considered the alternative hypotheses and corresponding scenarios.

In fact, there is no proof that Yvonne had already tuberculosis in 1928, only that she was ill enough for her husband to request a 5-year leave from the army because of her health. It is also possible, although less likely, that she initially suffered from another disease. However, more important, there is absolutely no proof for their hypothesis that Yvonne has been recovering in 1929-1931, on which all of their scenarios are based (the justification given is "Yvonne recovered enough to appear at Paul Billot's wedding in 1929" but attending the wedding of your brother-in-law at $300 \mathrm{~m}$ from your home is no proof of being in better health than 1 year before, especially when the precise health status 1 year before is not even known). In fact, the most likely is, on the contrary, that Yvonne's health only got worse, since in the March 1931 census she was not anymore counted in Arles, despite her husband and son being there, and in August 1931, she was photographed in a sanatorium in Leysin, ${ }^{8}$ then in March 1933 her husband renewed his 5-year leave from the Army, and finally, in January 1934 her death was recorded. So, the most likely scenario is therefore not even considered and evaluated in Zak and Gibbs' article.

2. Only some subjectively chosen evidences are considered:

For instance, the analysis simply drops all evidence that JC correctly remembered details and names of her early life, which her daughter was unlikely, or at least much less likely, to have known (in her case known second-hand) and known so well for even remembering the names in her old age.

3. Strongly subjective probabilities are used:

Almost all probabilities given are completely subjective estimates. For instance, about the 1945 photograph of JC, the authors consider one small detail of the photograph on the right eye, which they call "eye trauma" (in fact this seems to be simply a normal skin below the superciliary arch, on the illuminated side of the border between light and shadow) and they give a $10 \%$ probability for Jeanne's eye to be like that, and a $100 \%$ probability for Yvonne's eye to be like that. Other details of this photograph and most of the other available photographs are not considered in their analysis.

Another example: in their scenario where Yvonne dies, they estimate the probability that she "relapses", in 1930-1932 to only $1 \%$, although she was photographed in a sanatorium in August 1931 and was not counted with her family in Arles in March 1931.

Computing strongly subjective probabilities of a subjectively chosen subset of evidence in some subjectively chosen subscenarios cannot result in any indicator of the probability of JC's longevity to be authentic. The result may rather indicate the authors' strong subjectivity.

\section{Longevity Tree and Factors of Longevity}

\section{Ages at death}

JC has been living all her life in Arles, an agglomeration of 15,000 inhabitants at the moment of her birth, ${ }^{\dagger+1+\dagger \dagger}$ one of the oldest cities in France, located in Southern France at the starting point of the Rhône River delta. Arles was already, 2500 years ago, almost as vast as the neighboring Greek colony of Massalia (Marseille) and became a Roman colony under Julius Caesar. ${ }^{44}$

Without tracing JC's ancestry so far back in time, it is possible to find generations of her ancestors in the civil registration and parish registers of Arles, which start in the 16th century. ${ }^{16}$ Surprisingly, all of her 16 great-great-grandparents were living in Arles. Only at the sixth generation (fifth generation before her), two ancestors can be found who died away from Arles (in the neighboring town of Fontvieille).

In this article, we study the longevity of her ancestors through the sixth generation, inclusive. All the marriage certificates from these ancestors were found, all the death certificates were found except one at the sixth generation, and all the birth or baptism certificates were found except three at the sixth generation.

Therefore, a genealogical tree of JC's ancestors with the ages at death can be drawn for six generations, including JC (Fig. 6).

The generations' averages are indicated on the left. The background colors, shades of green or red, are based on the "longevity performance," which is defined below.

To focus on the ages, the names in this tree have not been noted except for the patrilinear line and JC's mother, but all names and dates can be found in Appendix A2. All names except for the sixth generation are also indicated in the tree of Figure 7, which in addition shows the extended family of Jeanne and her husband Fernand Calment, her double second cousin.

Data precision. For the 59 individuals in Figure 6 with all certificates found, the age-at-death is perfectly known.

For the three individuals with a missing baptism certificate, the date of birth can be estimated with a good precision

\footnotetext{
it+1 Arles counted 15,042 inhabitants in its agglomeration at the 1876 census, and 24,574 for the whole municipality. ${ }^{23}$
} 


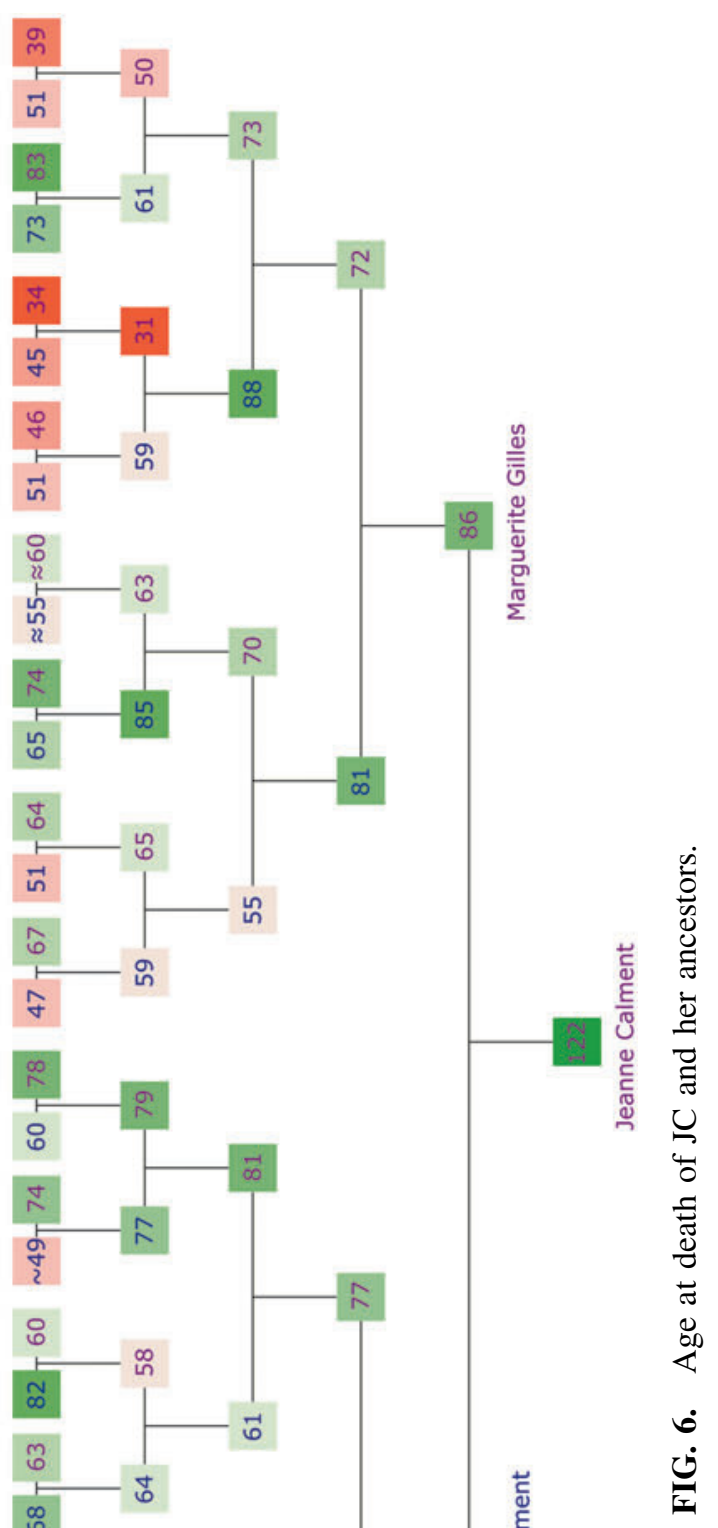

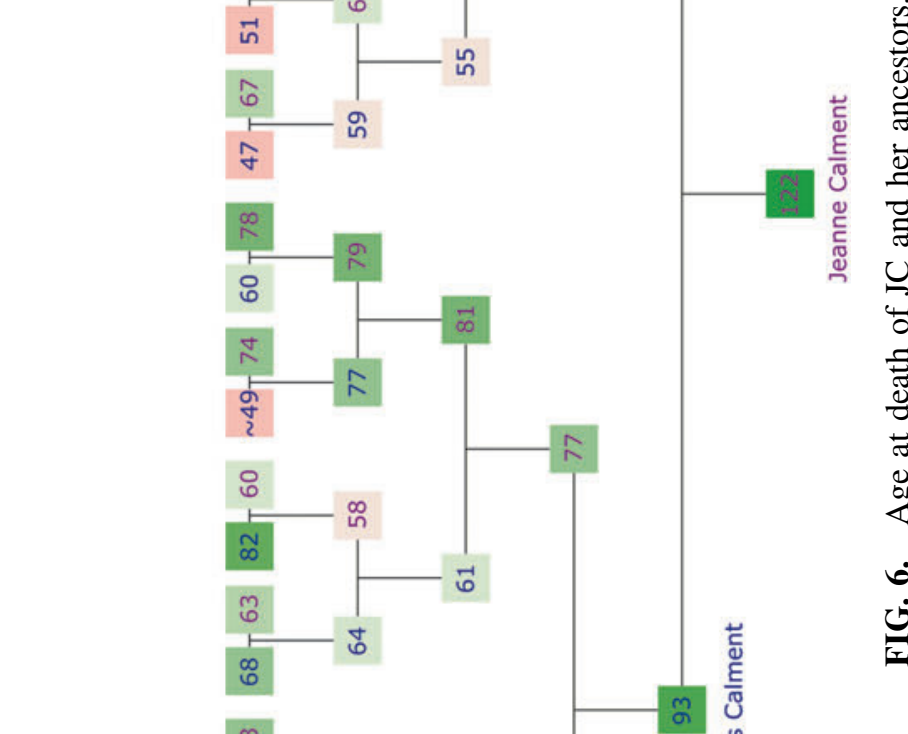

( \pm 2 years) because the age is given in the death certificate, with such relatively good precision; moreover, some additional information, such as the birth dates of siblings and the wedding date of the parents, sometimes allow narrowing the interval. The corresponding estimated ages are indicated with the sign $\approx$. The registers, not from Arles, where these certificates are expected to be written, apparently do not exist anymore.

For the only ancestor whose death record was not found, François Raynaud, the age precision is \pm 15.4 years $t+t+t$ and his age is noted with the sign $\sim$. As a result, the precision on the average age-at-death of the last generation (62 years) is below 1 year.

Exceptional age-at-death averages. Allard, Lèbre, and Robine, who had done with Caroline Bisson (Boyer) a very extensive research on JC's family, while she was still alive, noted the exceptional average longevity of JC's ancestors for the four generations preceding her and the fact that 18 ancestors out of $30(60 \%)$ in these generations had reached the age of $70,{ }^{1}$ of which $11(61 \%)$ survived over the age of 80 .

The analysis here includes the whole previous generation (sixth generation when JC is the first, born on average in 1718). At this generation, 11 ancestors out of $32(34 \%)$ became septuagenarians, and among them 2 (18\%) became octogenarians. While the average age-at-death of this generation, 62 years, is far less exceptional than these of the nearer generations, it is still above the average longevity, which 25year French people reached at the time (57.8 for men and 57.7 for women born in 1718 , according to our estimation of generation longevity expectancy described below).

According to the mortality tables, ${ }^{60}$ at the generation of JC's great-grandparents, born on average in 1783, the odds for reaching 80 years for a 25 -year-old French person were only $13 \%$, whereas $50 \%$ of JC's great-grandparents reached and often largely exceeded this age. For example:

Jean Baptiste Minaud died at 88, an age that a 25-year-old Frenchman born in 1792 , like him, had only a $2.1 \%$ chance to reach, and at the previous generation Marguerite Peyre died at 94 , an age that only $0.26 \%$ of the 25 -year-old French women born in $1781^{\S \S \S \S \S \S}$ would reach.

Longevity dissymmetry. JC's genealogical tree shows an important difference of average longevity between her maternal and paternal sides.

Most remarkably, the paternal grandfather, Antoine Calment (1803-1871), benefited from a very exceptional ancestry for the epoch with an average longevity of more than 85 years for both generations preceding him (Table 3), including the longest lived among JC's known ancestors, Marguerite Peyre (1741-1835), who died at 94.4 (fifth generation).

On the contrary, JC's maternal grandmother, Rose Minaud (1818-1890), has got the shortest lived ancestors, with

1H+t François Raynaud, born on April 27, 1718, died between August 18, 1752 (baptism record of his son), and May 24, 1783 (marriage of his son), that is, at $49.7 \pm 15.4$ years. He was the captain from a merchant boat, and so, he may have died away from Arles during one of his trips. This could explain why his death record was not found. His father Guillaume, also a boat captain, died in Arles at 85 in 1765.

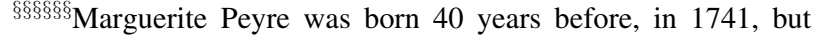
these data are not available before 1781 . 


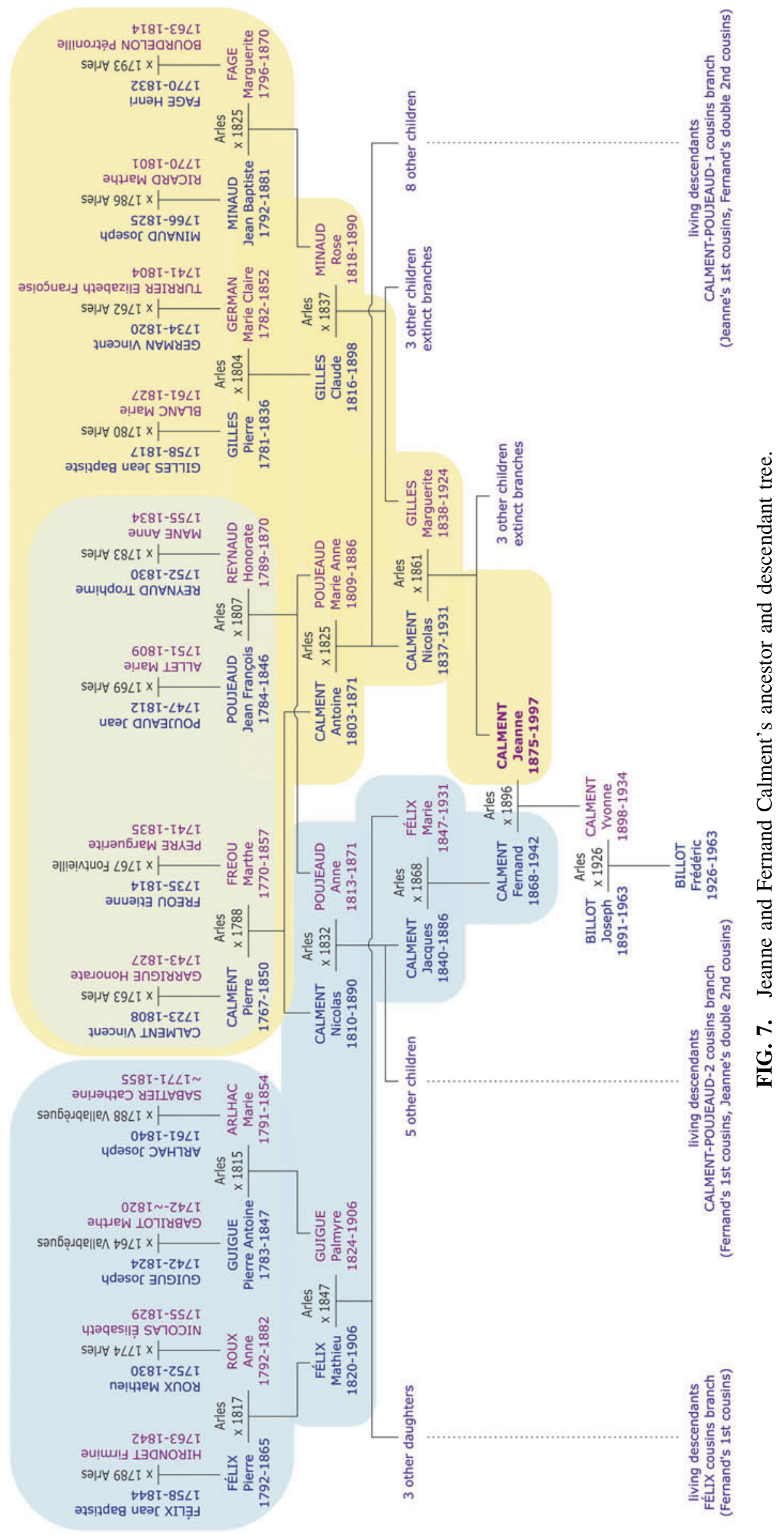


Table 3. Average Longevity of Each Generation of Grandparent Ancestors

\begin{tabular}{lcccccr}
\hline Generations & 1 & 2 & 3 & 4 & 5 & 6 \\
\hline Paternal grandfather & $\mathbf{1 2 2 . 4 5}$ & $\mathbf{9 3 . 2 2}$ & 68.36 & $\mathbf{8 5 . 4 7}$ & $\mathbf{8 5 . 6 1}$ & $\approx 66.60$ \\
Paternal grandmother & & $\mathbf{8 6 . 5 8}$ & $\mathbf{8 1 . 6 6}$ & 71.39 & 69.86 & $\sim 67.40$ \\
Maternal grandfather & & & 72.57 & $\mathbf{8 1 . 1 0}$ & 58.49 & $\approx 60.80$ \\
Maternal grandmother & & & &
\end{tabular}

Bold value: $>80$, italic value: $<60$.

paradoxically the notable exceptions of her father Jean Baptiste Minaud (1792-1881) and her maternal greatgrandmother Marguerite Gio (1747-1831), who both hold the longevity record of their generation, dying, respectively, at 88.35 and 83.88 , at the fourth and sixth generations.

Nikolay Zak suggested that the higher longevity of "the family members of ship carpenters" on the paternal side, compared with other ancestors, could be explained by their "prosperity" and "high social standing." 27 These are indeed certainly longevity factors, but they do not seem to be the main factors because in fact both the paternal and maternal ancestors from JC seem to be from rather equivalent social status and probably not very different wealth. In these five generations before JC, we find on both sides:

Wealthy farmers (a position called “ménager," keeping a large number of horses, which, in this Camargue region, have been often compared with the American cowboys running ranches): four on the paternal side and three or the maternal side.

Less wealthy farmers ("travailleur" in French): respectively, one and three.

Sailors: respectively, four (including three captains) and three (including two captains).

Ship's carpenters: respectively, three on the paternal side and one or the maternal side.

Millers or bakers: two bakers on the father's side, and three millers on the mother's side.

In any of the first four categories, at least one ancestor outreached 85 years. Among bakers and millers, the oldest age-at-death is, respectively, 64 and 81 .

The other occupations encountered are:

Paternal side: shoemakers (two), midwives (two), broker (one, after being a farmer), municipal councilor and wood merchant (one, after being ship's carpenter), and sister at the Charity hospital (one).

Maternal side: bourgeois (one), weaver (one), wheelwright (one, in addition to being a miller), and tobacconist (one, after being a sailor).

The highest social status among all ancestors, "bourgeois," is therefore found on the maternal side. This individual, Pierre Bourdelon (1720-1771), however, lived only 51 years and his wife 39 years. The longest lived ancestor, Marguerite Peyre (1741-1835), was the daughter of a "less wealthy" farmer and wife of a shoemaker.

\section{Longevity performance}

Definitions and demographical data used. The American biologist Raymond Pearl, one of the founders of biogerontology, and his daughter Ruth DeWitt Pearl have defined in 1934 the "computed average longevity" (CML) as "the total du- ration of life of a class of persons all living to [a certain] age," for instance 20, "before experiencing any mortality." 66 If considering the age 20 , they noted it CML $(20)=e_{20}+20$, where $e_{20}$ is the life expectancy at age 20 .

Here we will call:

"longevity expectancy at 25 " $\left(\mathrm{le}_{25}\right)$ the CML (25),

and "longevity performance," for a given individual whose age-at-death is known, the ratio between this individual's actual longevity and the $\mathrm{l}_{25}$ of his or her generation.

These terms were coined in French, in 2018, by Cyril Depoudent and Arnaud Le Page, who had calculated the longevity performance for JC and four generations of her ancestors. ${ }^{67,68}$

I calculated the longevity expectancy $\left(\mathrm{le}_{25}=e_{25}+25\right)$ and longevity performance for five generations of JC's ancestors, using the $e_{25}$ data, known for France since 1740, that is, for men and women born since 1715 :

Annual data for men and women born from $1781 .^{60} \mathrm{I}$ have used the generation's $e_{25}$, that is, the data for the yearly generation, per year of birth, and not the static $e_{25}$ of the current year (since the latter ignores the evolution of the mortality with time).

Decennial data for men and women born between 1715 and $1780 .{ }^{69}$ The available data for these years are only the static $e_{25}$, instead of the generation's $e_{25}$. I have therefore established an approximate estimate of the generation's $e_{25}$ based on the static $e_{25}$.

\footnotetext{
For generations whose date of birth $y$ is anterior to 1781 , the approximation done is:

$e_{25}$ generation $(y)=e_{25 \text { static }}(y+25)+\Delta(y+25)$, where $\Delta(x)$ is a function of difference between both expectancies. Since $\Delta(x)$ is already known for $x>1805$, I observe that for women, the decennial moving average of $\Delta(x)$, for $1805<x<1850$, is varying between -0.3 and +1.0 , which can mainly be explained by a small positive value representing the very slow progress of life expectancy in that period, plus some peaks when the static $e$ of the current year is degraded by wars or less favorable times (even for women). I observe also that more generally $\Delta(x)$ attenuates the variations of $e_{25}$ static. Given these observations and given the variations of the decennial $e_{25}$ static in the 18th century, I have arbitrarily estimated $\Delta(x)$ as follows: $\Delta(1805)=\Delta(1806)=2.29 ; \Delta(1795)=1 ; \Delta(1785)=$ $2 ; \Delta(1775)=0 ; \Delta(1730)=0 ; \Delta(1745)=1.5 ; \Delta(1715)=0$; and some linear interpolation between these values.

The decennial $e_{25}$ static values have also been linearly interpolated to get annual values. Then the basic approximation of $e_{25}$ generation could be calculated.

For men, the decennial $e_{25}$ static is not known for the 1790s and 1800 s, and I have therefore approximated that the decennial value for men in the 1790s was the same as for women, which is not exact as it neglects some important effects of the French Revolutionary wars, but this allows to use the same $\Delta$ function for men and women, and since JC's ancestors did not die at war in this period, it seems anyway even better to compare their longevity with men neither affected by the wars. Overall, this simple estimation of $e_{25}$ generation is approximate but good enough for our objective here of calculating an indicator of longevity performance.
} 
For the 14 ancestors born before 1715 (mean 1704, range 1692-1711), as an approximation, I considered the static $e_{25}$ as being the same in these years as in the 17151725 decade, that is, 31.3 years for men and 31.2 years for women, from which I estimated the generation's $e_{25}$ with the same method as for the later years. ${ }^{\dagger \dagger \dagger \dagger \dagger \dagger}$

Tree of longevity performance. In Figure 8, the same tree as Figure 6 indicates the figures of longevity performance for JC's ancestors and the averages per generation.

Progressive concentration of longevity factors in JC's ancestry. The progression, from generation to generation, of the average age-at-death at a faster pace than in the general French population (see the increase of the longevity performance averages at Fig. 8), suggests a progressive concentration of favorable factors of longevity in JC's ancestry.

Allard and Robine ${ }^{73}$ had noted the same progression when comparing with a control group (one control individual for each ancestor, married at the same place and period, and who also had children): 1.0, $+4+1+1.3,1.4,1.5$, and finally 2.1 longer lives for JC's parents than for the control.

Time line representation. A time line representation of the age-at-death from JC and each of her ancestors, together with the generation's longevity expectancy in France, is drawn in Figure 9. The linear interpolation and the mean represented here include JC for women. Her brother François Calment, who died at 97, has also been represented but is not included in the mean and interpolation calculus for men.

Most of the points and the linear interpolations are largely above the longevity expectancy at 25 years of the corresponding generations, showing here also how JC's ancestors performed significantly better than their French contemporaries, especially the last three generations before JC.

The Fig. 9 graph finishes in 1900, but the longevity expectancy at 25 continued to grow in the 20th century in such a way that JC's family can be considered to be simply well ahead of its time in terms of longevity. As a comparison, the $\mathrm{le}_{25}$ for the generation born in France in 1996 has been calculated at 92.78 years for women and 87.28 years for men (this figure, calculated in 2001, is an extrapolation). ${ }^{60}$ Interestingly, these 1996 generation figures are about the same as the longevity of JC's parents, who died, respectively, at 86.58 and 93.22 , although they were born in $1837 /$ 1838 , more than 150 years before.

The generation born today has therefore parents who will die around the same age as JC's parents; this generation has probably got a similar immediate-ancestors longevity history as her. Does this mean that many of them will reach 120

${ }^{\dagger+1+\dagger \dagger}$ As a comparison, the $e_{0}$ data in England show some limited variations during this period (quinquennial values from 1693 to 1718 being $36.3,38.1,38.5,36.9$, and 35.8$),{ }^{70}$ while the $e_{25}$ in some categories of the Dutch population increased by about 4 years between the 50-year intervals $1650-1700$ and $1700-1750,{ }^{71}$ and the $e_{60}$ of catholic cardinals (mostly born in Italy) increased by about 1 year between the 25-year intervals $1675-1699$ and 1700-1724. ${ }^{72}$ 1 instead of 32 here.

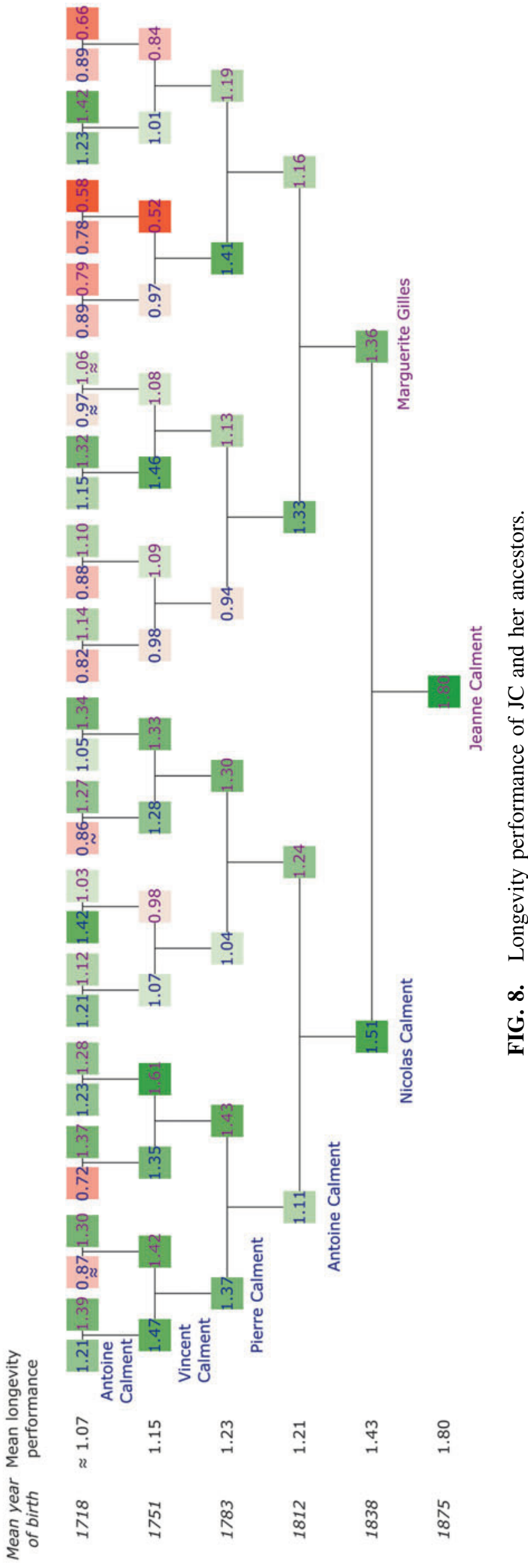



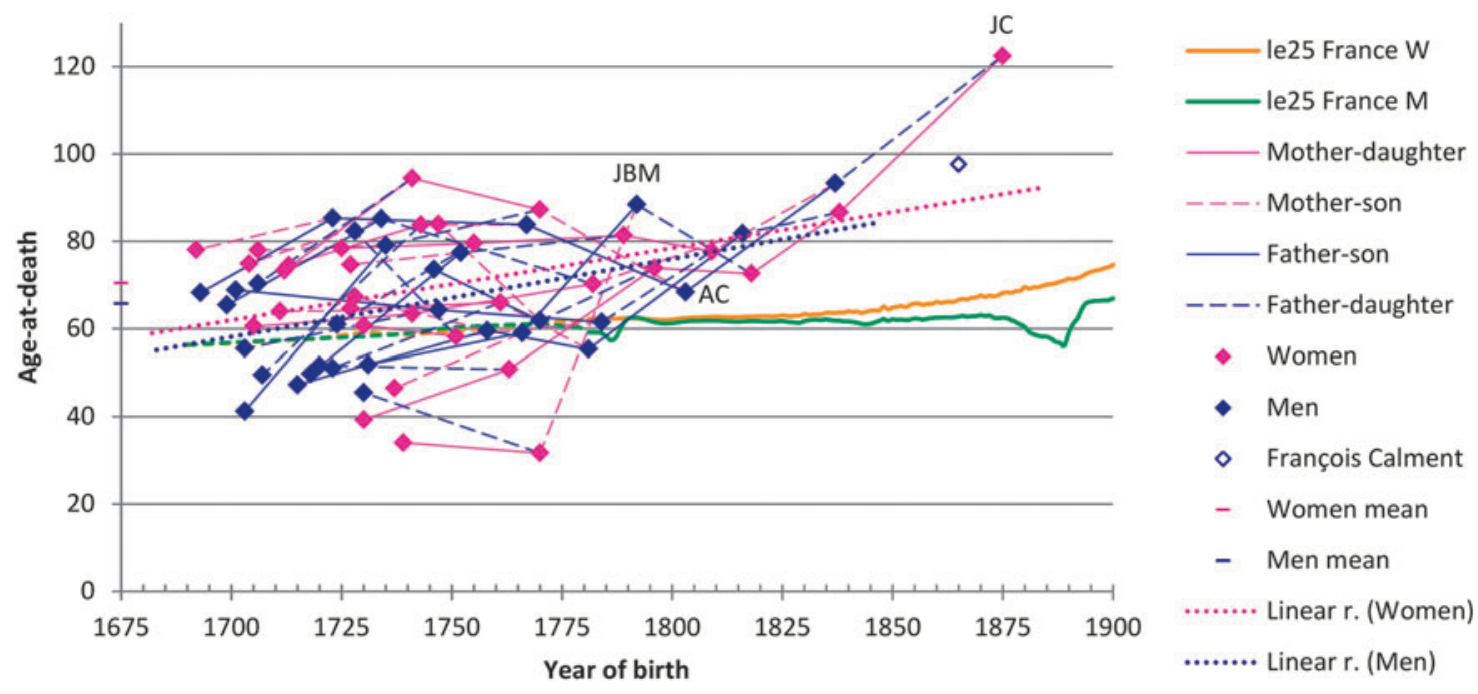

FIG. 9. Age-at-death of JC's ancestors compared with the generation's longevity expectancy at 25 .

years? Only time can answer this question; however, it is probably not equivalent in terms of longevity potential to perform the same, but in a more favorable environment.

Fatherhood and motherhood cannot explain the remarkable longevity observed. Pearl and his daughter ${ }^{66}$ observed that the $l_{20}$ and $l_{30}$ seemed to be higher for fathers and mothers than for men and women without children; however, he could not conclude because the data sets he compared were not for the same populations. More recently, Kaptijn et al. ${ }^{74}$ showed that in the Dutch population born in the second half of the 19th century, $e_{50}$ of ever-married men and women was correlated with the number of children born: a positive association for fathers (the more children, the longer life), with between 1 and 2 years of additional life expectancy compared with nonfathers, and an inverse U-shaped association between fertility and longevity for women, having a maximal longevity with two children (almost 3 years more than ever-married women without children) and a nonsignificant gain with five or more children.
Since we are here considering only mothers and fathers, a better longevity performance could be expected than for the general population, maybe up to 2 or 3 years of increased average longevity. However, even 3 years of increased longevity would represent less than a $5 \%$ increase for the generations born after 1750, while these generations of JC's ancestors achieved, respectively, a 15\%, 23\%, 21\%, and $43 \%$ increased longevity. Parenthood cannot explain the observed longevity overperformance.

The factors involved could be genetic and/or environmental, such as the wealth and social status of JC's ancestors.

Comparison with King George V. To get an indicative reference for the wealth and social status hypothesis, as a comparison, the same chart can be drawn for the King of the United Kingdom, George V (1865-1936) who was born just 1 month after JC's brother François Calment (1865-1962) and whose ancestry is well known ${ }^{75}$ (Fig. 10).

Figures 10 and 11 show how George V's ancestors compare with JC's ancestors in terms of longevity. The
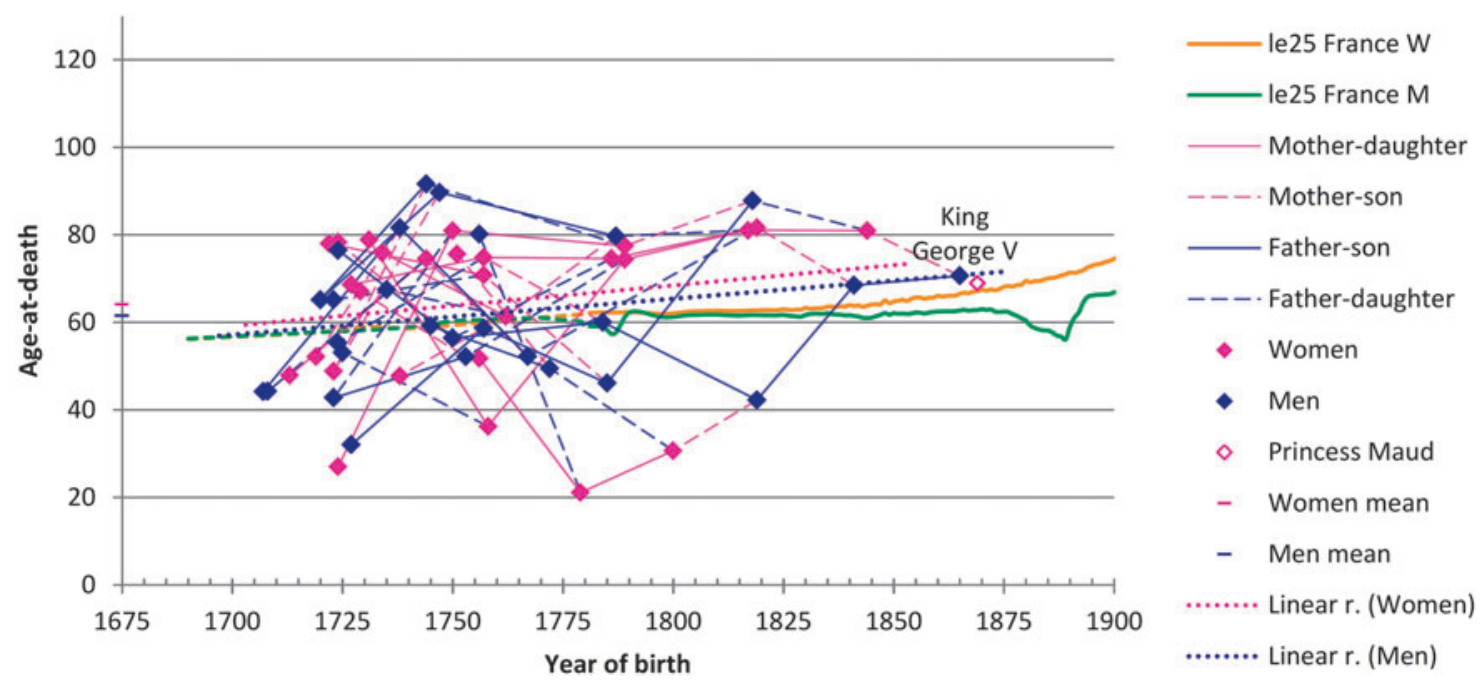

FIG. 10. Age-at-death of King George's ancestors, and generation's longevity expectancy at 25. 


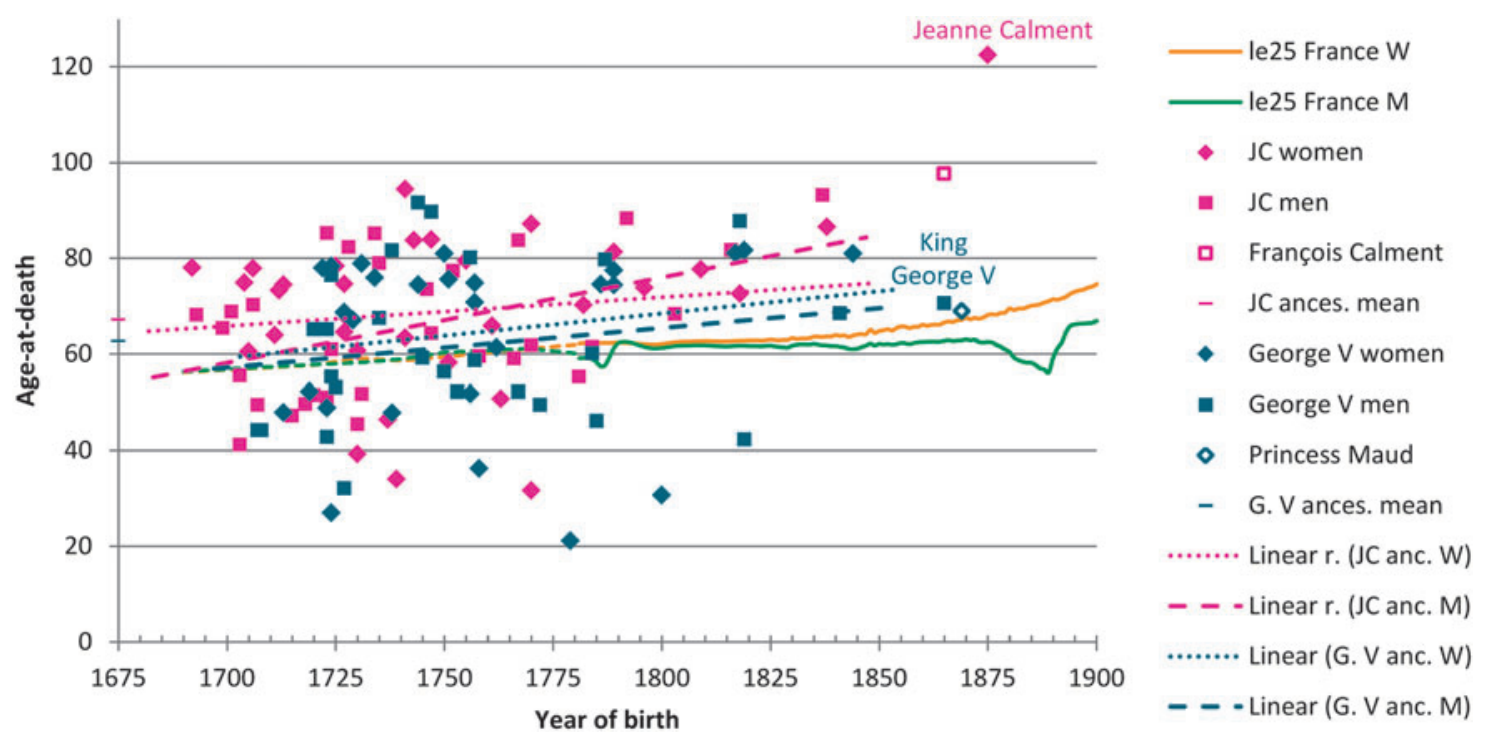

FIG. 11. Age-at-death of JC's and King George V's ancestors, and generation's le 25 .

longest lived of his three sisters, Princess Maud (18691938), who became Queen of Norway, is also represented, in the same way that François Calment is represented. The means and linear interpolations on this graph are for the ancestors only. There are fewer dots for King George V since nine of his ancestors are twice his ancestors. These are therefore counted twice for the means and interpolations.

Despite his unbeatable social status, King George V's ancestors were, on average, shorter lived than JC's (62.71 compared with 67.19), and notably his parents (74.73 compared with 89.90) and his longest lived sibling (68.98 compared with 97.60).

While this is only one example, with individuals living on the territories of the current Great Britain, Germany, and Denmark, and should be completed with more extensive data, this suggests that the relatively good wealth and social status from JC's ancestors likely cannot explain alone their remarkable longevity.

\section{Total immediate ancestral longevity}

Total immediate ancestral longevity score and average. The total immediate ancestral longevity (TIAL) score, introduced in 1934 by Raymond Pearl and his daughter, ${ }^{66}$ is defined as the sum of the ages at death from the parents and grandparents.

This score divided by 6 is therefore the average age-atdeath from these immediate ancestors and we call this "TIAL-a" (it has also been called "adjusted TIAL score",76).

For JC and three generations of her ancestors, these TIAL-a average ages are represented in Figure 12.

The TIAL score of JC had already been calculated by Robine and Allard, ${ }^{73}$ as being 477, which is indeed her TIAL score when calculated in the same way as Pearl and Pearl did when they introduced the TIAL score, using the usual round ages (rounded down).

Here I calculated 480.12 because I used the exact decimal ages-at-death. Statistically, there is a 3-unit difference between both calculus modes, which is also the difference in the case of JC.
This TIAL score, corresponding to an average age-at-death of her parents and grandparents (TIAL-a) of 80.02 years, is very high for the epoch. In the study where Robine and Allard identified a control individual for each of JC's ancestors, ${ }^{73}$ the average age-at-death of the controls for JC's parents and grandparents was $\sim 48.7$ years (TIAL 289 plus 3 divided by 6).

As other points of comparison, King George $\mathrm{V}$ had a TIAL-a of 73.72 years, whereas some famous scientists had their TIAL calculated by Sri Kantha, ${ }^{76}$ which when converted into approximate TIAL-a, are for Einstein (1879-1955), Darwin (1809-1882), Irène Joliot-Curie (1897-1956), whose sister Eve died at 102, and Aage Bohr (1922-2009), respectively, 65.5, 63.5, 62.5, and 73.2. Desjardin ${ }^{77}$ showed that the TIAL-a of the parents and grandparents of Marie-Louise Meilleur (1880-1998), who succeeded JC as the oldest living human, was 84 (TIAL 501).

To get a more statistically significant reference, we can compare with the average, for the French population, of the six $l_{25}$ generation corresponding to each of the years of birth of the six JC's immediate ancestors. This average is 62.36 years.

Allard, Lèbre, and Robine also made a particularly interesting and significant comparison, which they explain in their book ${ }^{24}$ : thanks to a very extensive genealogical research, they identified 77 individuals from JC's family at her generation (herself and her siblings, plus her first and second cousins). Then they also calculated JC's TIAL-a as being 80

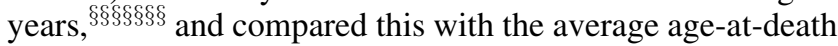
of the parents and grandparents from her cousins whose ageat-death was known (the vast majority), which is a sort of aggregated average TIAL-a from her cousins. This average that they calculated was only 58 years.

TIAL ratio. An indicator of how an individual performed for longevity compared with his or her parents and grandparents, which I introduce here, is the ratio between the longevity and the TIAL-a of the individual, which we will

\footnotetext{
$\S \S \S \S \S \S \S$ They do not use the acronym TIAL in this book.
} 


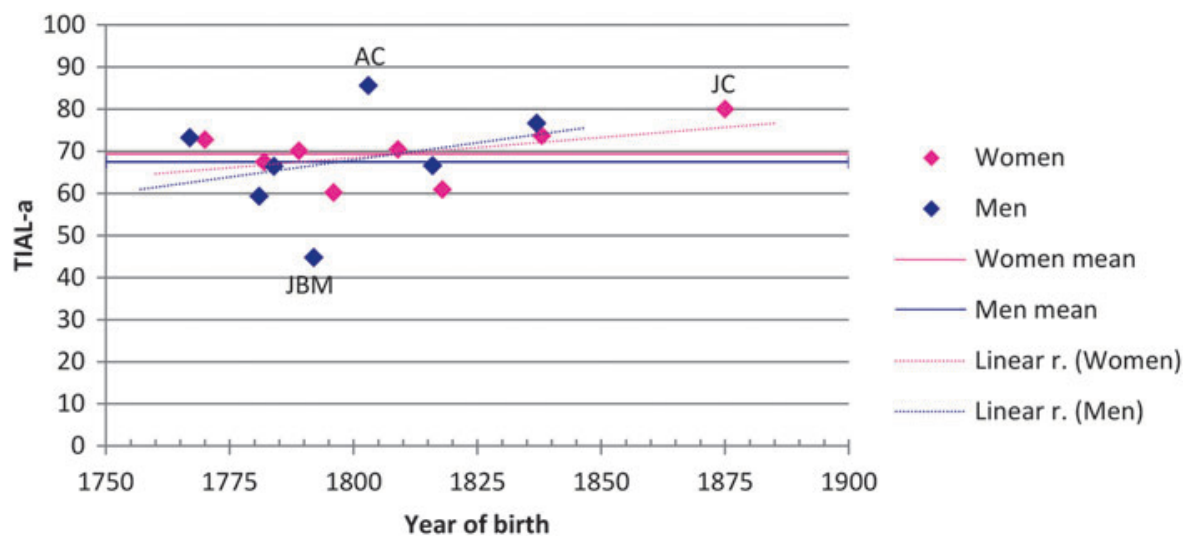

FIG. 12. Average age-at-death of immediate ancestors (TIAL-a) of JC and her ancestors. TIAL, total immediate ancestral longevity.

call "TIAL ratio." This ratio for JC and her brother and ancestors is represented in Figure 13.

Interestingly, most of the TIAL ratios are plotted remarkably near their average, almost all of them for women and almost half of them for men. The average is 1.20 for women, including JC (standard deviation 0.14), 1.16 for women without JC (standard deviation 0.06) and 1.17 for men without François Calment (standard deviation 0.36), showing that in the generations represented, the ancestors of JC regularly overperformed their immediate ancestors, by an average of $17 \%$, corresponding to $10 \%$ per generation.

It would be expected that women would have a better TIAL ratio than men, since they usually live longer than men and the TIAL is sex-independent, but this is not observed in JC's ancestors.

JC cumulates both excellent score and ratio. As can be seen in these two graphs (Figs. 12 and 13), JC combined two factors which led to her exceptional longevity of 122.45 years:

1. She had an excellent TIAL, 480.12, that is, 80.02 years on average (TIAL-a).

2. She largely overperformed her TIAL-a, with a ratio of 1.53 .

However, among her ancestry she was not the one with the highest TIAL, and neither the one who overperformed his or her TIAL the most:

Her grandfather Antoine Calment (noted "AC" in the graphs) had a TIAL of 513.39, that is, 85.56 years on average, which is absolutely exceptional for the epoch. However, he is also the one who underperformed it the most, with a death at 68.36 years, a ratio of only 0.8 .

Her great-grandfather Jean Baptiste Minaud (noted JBM in the graphs) overperformed his TIAL with an impressive ratio of 1.97 , dying at 88.35 years while his TIAL, the worst of all, was at only 268.44 , that is, 44.74 years on average.

To convert the TIAL ratio $x$ into the equivalent ratio $y$ per generation, one can observe that for a family with constant progression ratio $y$ between generations, $x=\operatorname{age}_{\text {gen } 1} /$ TIAL-a $=\operatorname{age}_{\text {gen } 1} /$ $\left[\left(2 \mathrm{age}_{\mathrm{gen} 2}+4 \mathrm{age}_{\mathrm{gen} 3}\right) / 6\right]=6 y^{2} \mathrm{age}_{\mathrm{gen} 3} /\left(2 y \mathrm{age}_{\mathrm{gen} 3}+4 \mathrm{age}_{\mathrm{gen} 3}\right)$ which solution is $y=x(1+\sqrt{ }(1+24 / x)) / 6$
To understand why these three extreme cases of JC's tree are outliers, it is interesting to examine the performance of their siblings:

1. JC's only brother who survived childhood (two other siblings died under 4), François Calment, died at 97.6, overperforming his TIAL by a ratio of 1.22 (compared with 1.17 for his ancestors whose longevity trend he thus slightly accelerated), and overperforming his French 25-year-old contemporaries by $56 \%$.

2. Antoine Calment's (1803-1871) record TIAL was no coincidence since all his grandparents had at least one other long-lived sibling: Marie Anne Calment, 88 (1725-1814); Delphine Garrigue, 90 (1748-1839); Jeanne Garrigue, 82 (1754-1837); Marie Freou, 83 (1740-1823); Marguerite Freou, 84 (1742-1827); and Jean Peyre, 86 (1755-1842).

Yet, he and his eight siblings (at least) all survived childhood, but all died younger than their parents and grandparents (at 18, 38, 40, 49, 50, 68, 73, 79, and 80 years). Paradoxically, their father, Pierre Calment, who died at almost 84 years and had a midwife mother, had on the contrary all of his seven siblings dying before 7 , except one brother who survived childhood but died at 25 . One hypothesis, therefore, could be that Antoine and his siblings were less exposed to infections in childhood than their father, which may have resulted in developing less immunity against diseases and thus a lower longevity. However, in a study on centenarians born in 1890-1891 in the United States, Gavrilov and Gavrilova found no effect on longevity from higher child mortality in the household. ${ }^{78}$

Another factor possibly unfavorable to longevity is that they grew up in a certainly less prosperous economic environment, first because the nine siblings, born between 1790 and 1810, having all survived, had to share more the resources and attention of their parents, and second because of the economic difficulties in France and specifically in Arles during the troubled 1790-1800 period, ${ }^{44}$ plus after 1806 when the English naval blockade of the French coasts had deeply impacted the economy of Marseille. It is not clear, however, how the Calment family, who had become ship builders just before the Revolution, was 


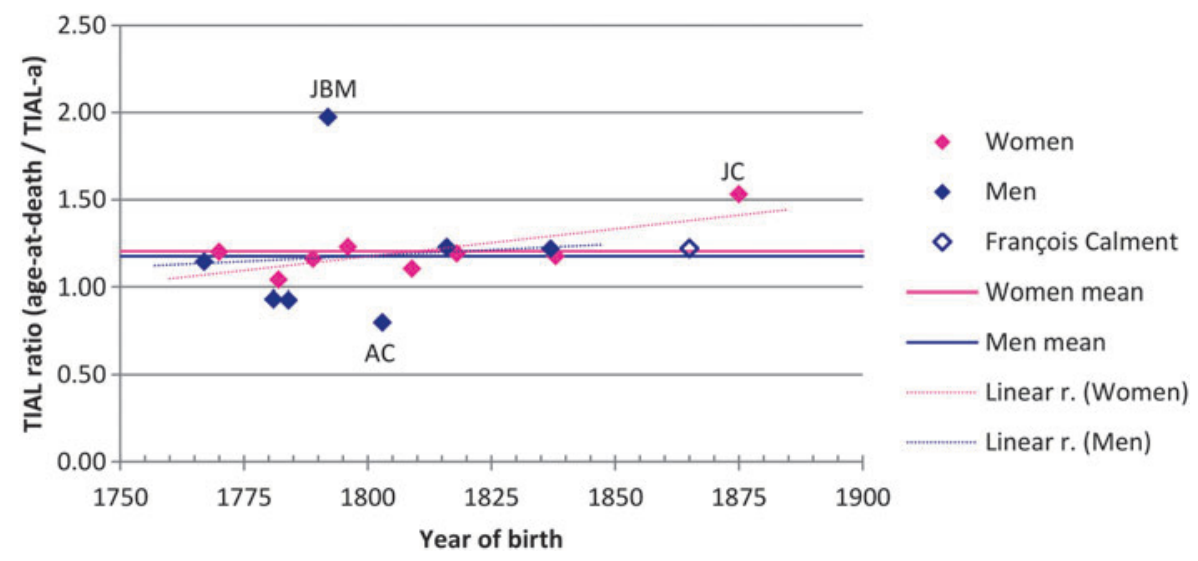

FIG. 13. TIAL ratios for JC and three generations of her ancestors.

personally affected by this, because while the Marseille's fleet of merchant deep sea ships had dramatically decreased from 330 to 9 in a 4-year period around $1810,{ }^{79}$ the boat construction industry might have been only modestly impacted in Arles where its merchant fleet, essentially river and coastal boats, rose from 68 units in 1758 to 90 units in $1808^{44}$ and decreased to 78 in $1813 .{ }^{80}$

3. Jean Baptiste Minaud (1792-1881): His muchincreased longevity compared with his immediate ancestors cannot be explained by a change in social status, since he was a sailor such as his grandfather Jean Ricard (1730-1776) who had become a boat captain before he died at 45 . His siblings remain to be studied. One potential explanation could be that his immediate ancestors had simply been unlucky with accidents or diseases.

\section{Factors for JC's longevity}

Combination of excellent heredity and excellent environmental factors. If the TIAL can be viewed as a basic indicator of the hereditary factors of longevity, and if the TIAL ratio can be viewed as a basic indicator of the evolution of environmental/behavioral/chance factors compared with the parents and grandparents, this illustrates that JC cumulated both an excellent heredity and some excellent other factors.

Indeed, JC obviously concentrated a large spectrum of environmental factors favorable to longevity. The aim of this article is not to give an exhaustive list of these factors but the following were met by JC:

Positive, happy, and optimistic character, with a good sense of humor. ${ }^{24,41}$

A good conation, that is, an active state of mind, easily initiating and executing actions ${ }^{81}$; independent character. ${ }^{41}$

Meditation (praying every evening at the church until the age of $108,{ }^{82}$ and when at the retirement home still praying every morning facing the window ${ }^{41}$ ).

Regular complex mental activity (piano ${ }^{24}$; always avid to learn and discover ${ }^{41}$; after 110 , listening daily to the news, morning and evening, with her Walkman ${ }^{41}$; etc.).

Regular physical activity (lots of sport in her young years; riding a bicycle till $100^{41}$; daily morning gym even after
$110^{83}$; walking daily to the St. Trophime church till 108 and climbing its famous stairs ${ }^{82}$; walking daily, no matter the weather, to the cemetery at $1 \mathrm{~km}$ from home ${ }^{41}$; climbing stairs at home till 110, and at the retirement home till 115; etc.).

Healthy diet (Mediterranean diet, ${ }^{+1+t^{+}+\dagger \dagger}$ with olive oil and lots of garlic, ${ }^{17}$ including her weekly preparation of ailoi with four cloves of garlic ${ }^{41}$; every day a homemade fruit salad of bananas sprayed with orange juice ${ }^{41}$; chocolate after each meal ${ }^{+f+1+441}$; etc.).

Good and regular sleeping patterns (at the retirement home she was sleeping "like a baby" from 10 pm to $6: 45$ am, and having a 2-hour nap in the afternoon). ${ }^{41}$

Wealth (which means no stress nor worries for the material aspects of life).

Good environment in France with a high life expectancy, especially for women (in 1997, the life expectancy at 80 years for women was in France by far the highest of Europe with 9.8 years, before Italy and Switzerland at 9.2 years $^{85}$ ),

And, moreover, apparently a high rate of long-living women in Arles compared with France: the ratio 95+ women per $75+$ women was $2.8 \%$ in Arles in 1990 , the fourth highest among the 114 French communes of

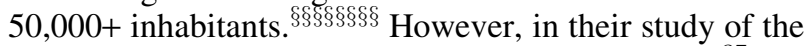
Arles' 1886 and 1895 birth cohorts, Cournil et al. ${ }^{87}$ did not observe such a phenomenon. Aggregated data from the Arles' 1880-1895 birth cohorts may help understanding the reasons for this discrepancy since the 1990s Arles population of $95+$ women was only a few dozens.

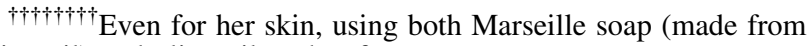
olive oil) and olive oil on her face.

Whe could eat more than a kilo of chocolate per week. ${ }^{24}$ Chocolate consumption has recently been found to be associated with longer telomeres. ${ }^{84}$

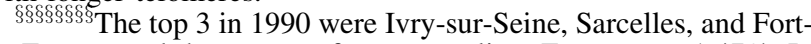
de-France, and the average for metropolitan France was $1.47 \%$. In 1968, 1982, and 1999, this ratio in Arles was, respectively, 0.9\%, $1.4 \%$, and $3.3 \%$ compared with the national average of $0.66 \%$, $1.07 \%$, and $2.54 \%$, ranking $27 \mathrm{th} / 121,27 \mathrm{th} / 115$, and $18 \mathrm{th} / 124$ in France (the population per age figures are extrapolated from a $25 \%$ sample of the census, therefore starting to be fairly significant here only from 1990 when the $95+$ female population in Arles was estimated to $68=4 \times 17){ }^{86}$ 
Also, JC had the remarkable habit of not heating her home, which is the reason why, when the pipes had frozen during the exceptionally cold 1985 winter, ${ }^{* * * * * * * * * * *}$ the firemen, who could not unfreeze them, had to take her to the retirement home, although, at almost 110, she was otherwise still able to live independently. ${ }^{41}$ She explained that this no heating habit was "in order to kill microbes and not soften herself." ${ }^{41}$ While such a strategy may not kill microbes and may on the contrary favor respiratory infections, ${ }^{90}$ it might, however, have a positive effect on longevity since some studies suggest that a cooler body temperature is associated with an extended life span. ${ }^{91}$ The human deep body temperature is regulated, such as for all homoeothermic animals, but it has been shown that frequent prolonged exposure to cold environmental temperatures could slightly lower the human deep body temperature. ${ }^{92}$

The only potentially negative factors for longevity that have been mentioned about JC are that she was:

smoking up to one cigarette after each meal, that is, two maximum per day, until the age of 117 when she decided to stop $^{41}$; however, in fact this was no more than three per week maximum, according to the personal estimate from Claudine Serena, a nurse from the retirement home who has been there during the whole 12 years of JC's

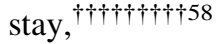

and drinking a little bit of port wine after lunch. ${ }^{41}$

Nevertheless, these were quantitatively very limited, and moreover, a moderate red wine consumption has been shown to be associated with a lesser risk for coronary heart disease. ${ }^{93}$

Also, the fact that her daughter and grandson died both at 36 , respectively, from "pleurisy" (according to JC but this certainly means tuberculous pleurisy, as confirmed by the family) and car accident, ${ }^{41}$ could have had a negative impact on JC because of the sadness caused; but at the same time it may on the contrary have forced her to develop an even more resilient mind.

\section{DNA and Blood Cell Analysis}

\section{Biological factors for longevity}

As for several hundreds of French centenarians, some blood samples from JC have been collected, in a project called Chronos, conducted by the Centre d'Étude du Polymorphisme Humain (CEPH, in Paris, now also called Jean Dausset's Foundation after the name of his founder, Nobel Prize in physiology or medicine). The cells and DNA are reportedly still stored in Paris. ${ }^{94}$ Therefore, the analysis of JC's DNA and cells would technically be possible from these samples, provided that ethical and juridical aspects are addressed, especially in consideration to the family.

Such an analysis could be immensely valuable to understand the genetic factors and characteristics of JC's excep-

\footnotetext{
$-12.2^{\circ} \mathrm{C}$ recorded in Nîmes in January 1985 , the coldest temperature since 1956 and unbeaten since then. ${ }^{88,89}$

the retirement home JC was not able to buy cigarettes herself, and asked occasionally for one to visitors or staff. Claudine Serena does not even remember seeing ever a packet in her room. Also, for smoking JC had to be accompanied outside by a member of the staff and they were not often available for such thing. ${ }^{58}$
}

tional longevity, which could lead to discoveries valuable for understanding the mechanisms of aging and longevity, like it has been the case already with the analysis from the cells of another oldest human, Hendrikje Van AndelSchipper, who died at 115 in 2005 (Holstege et al. ${ }^{95}$ ).

\section{Authenticating the samples}

Authenticating these samples would not require any exhumation. First of all, the CEPH knows from whom they collected each of the samples. Second, it is easy to check if the human leukocyte antigen type of the sample is the same as the one from JC, which has been published by Dr. Garoyan in his thesis in $1990 .{ }^{57}$ Moreover, to further authenticate the sample, a simple comparison with the DNA of a living relative of JC (which requires of course his or her consent) could confirm that the sample is the one from JC and not from another centenarian.

In addition, and although the strength of the current validation does not make it necessary, a DNA analysis of the existing samples would permit to address the last doubts that some may still have about the hypothesis of an identity swap between JC and her daughter Yvonne. This can be done by three possible methods (the last two would involve a voluntary participation of some family members):

1. The level of autozygosity (homozygosity by descent) of the DNA is a distinctive feature between Jeanne and Yvonne Calment, because Yvonne's parents were double second cousins, which means that Yvonne has only 24 distinct great-great-grandparents as opposed to a full 32 for Jeanne, provided that the genealogical tree (Fig. 11) coincides with the biological tree. As a result from this consanguinity, Yvonne has got a coefficient of inbreeding her DNA is expected to show this level of autozygosity, located on a number of relatively large autozygous DNA segments, whereas Jeanne, who has got all her 128 ancestors distinct at the eighth generation, would have a very small level of autozygosity, from distant ancestors, spread on only very small segments of autozygous DNA.

Some effective autozygosity analysis methods are available, for instance, the FEstim method ("F estimation"), ${ }^{97}$ a maximum-likelihood method using a hidden Markov model, and its improved multipoint version described in 2010 by Polašek et al., ${ }^{98}$ and further improved for dense single-nucleotide polymorphism genome-wide maps in 2011 by Leutenegger et al. in a study performed at the CEPH. ${ }^{99}$

2. The DNA comparison with a Yvonne Calment's paternal grandmother's relative would show the level of common DNA ${ }^{\S \S \S \S \S \S \S \S \S}$ of a relatively close family link ( $1.56 \%$ on average for a second cousin once removed) in the case where the sample would be Yvonne's

\footnotetext{
f+ft+t+The coefficient of inbreeding, also called "coefficient of consanguinity," is defined as "the probability that two alleles at a given locus are identical by descent. i.e., the extent to which an individual is more likely to be homozygous rather than heterozygous because of related parents." 96

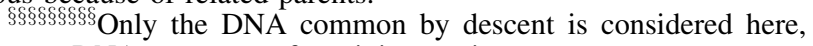
that on DNA segments of a minimum size.
} 
DNA, but not in the case where the sample would be Jeanne's DNA (provided that the relative is not closely related to JC on other sides of his or her ancestry, which could be verified). There exist some living descendants of the same matrilineal line as this grandmother, which would allow suppressing any possibility of discrepancy between the biological tree and genealogical tree (except for Fernand Calment's fatherhood, but it is extremely unlikely that Fernand was not the biological father of Yvonne, because she was the first child of the couple, born less than 2 years after the wedding, because her parents were cousins who made this wedding from their own loving choice, and in addition, in the photographs she resembles him).

3. The DNA comparison with several Jeanne and Yvonne Calment's living relatives would allow calculating some genetic probabilities for the sample to be Jeanne's versus Yvonne's, depending on the amount of common DNA found and the size or number of common DNA segments (statistically smaller common segments in Yvonne's case because the genetic distance would be one more meiosis away). However, due to the fact that the closest living relatives are descendants from first or second cousins of JC (Fig. 8), plus the fact that most of them are also related to Fernand Calment (meaning at best $3.13 \%$ of expected common DNA with Jeanne or $2.34 \%$ with Yvonne), the confidence intervals for these two parameters (percentage of common DNA and average segment size of the common DNA segments) around the expected values are large and overlapping between Jeanne and Yvonne. This means that the comparison would need to be made with several living relatives, ideally from different branches of the family, to reach a good level of certainty in the probability to be Jeanne versus Yvonne. Therefore, the two other methods are easier and more precise.

\section{Conclusion}

$\mathrm{JC}$ is a true pioneer of longevity. It was not very likely, about a $7 \%$ chance, that the first validated "hypercentenarian" who would establish such a record of 122 years would be born in the 19th century, but there was a substantial possibility that this $7 \%$ chance would happen and the very large available evidence entirely supports that this age was indeed reached by JC. On the contrary, the hypothesis of an identity swap with her daughter appears not even realistic given the context and the facts, and not supported by evidence. As a consequence, this record is very strongly validated.

It is part of the essence of pioneers to establish unlikely records. It was not very likely, either, but possible, that a man, rather than a woman, Geert Adriaans Boomgaard (1788-1899), would be the first validated supercentenarian in the 19 th century ${ }^{100}$ (the sex ratio for supercentenarians born in the G7 countries between 1850 and 1900 is 11 women for 1 man, as per the GRG database, while for centenarians born in the same period, the sex ratio is 4.4 , as per the HMD database).

According to the mortality models and the increasing numbers of new centenarians each year, it is highly likely that
JC's record will be matched and exceeded before the end of the 21 st century, most probably by a woman in Japan, a country where in 2016, for the first time, more women became centenarians than in the United States despite a much smaller population, ${ }^{6}$ and where women currently live, on average, the oldest in the world, ${ }^{101}$ after Monaco, ${ }^{102}$ with a 87.32 life expectancy at birth in $2018 .^{103}$ The number of Chinese centenarians is also rapidly increasing and surpassed the number of Japanese centenarians in 2014, reaching 58.789 in June 2014, according to the Gerontological Society of China (at the same date there were about 57.000 centenarians in Japan and 60.000 in the United States, according to the HMD data). ${ }^{104}$

However, JC's record will still hold at least for a few years or decades (at the earliest it could be beaten by the currently oldest living human, Kane Tanaka, who would reach 122 only in 2025 , in the unlikely hypothesis that she survives so old).

While one should expect even longer living cases in the future, today a lot can be learned about longevity from JC's very unique case.

\section{Acknowledgments}

This research could not have been conducted without the previous studies made about JC, and especially the work from Dr. Michel Allard and Jean-Marie Robine, who, together with Dr. Victor Lèbre, had the invaluable initiative of meeting many times with $\mathrm{JC}$ and recording numerous interviews with her, and who recently, together with Pr. François Herrmann and Dr. Bernard Jeune, published an article $^{8}$ containing some mortality models that I used. I would like to respectfully thank them all. My warm thanks go also to the family, who kindly provided testimonies, letters, and photos: Claudie Taque, Frédérique Skyronka and her father, Martine Crouanson, Gilberte Méry and her grandson Tom Méry, and Claude Chaix. The Facebook group "Contre-enquête sur l'enquête Jeanne Calment," founded in January 2019 in Arles by Cécile Pellegrini, moderated by Brigitte Jajcaj, Claudine Serena, Emmeline Foubert, and Mélanie Perny-Villeneuve, was also particularly useful as a meeting and debate place for many individuals who contributed in the (counter-) investigation. I cannot name here all the over 1500 members and detail each individual contribution but I would like to thank especially, in addition to the ones mentioned elsewhere in this section: Matthieu Alexandre, Silvie Ariès, Julien Arlandis, Francis Aurran, Michael Bailly, Colette Barbé, Corinne Benady, Natalie Coles, Muriel Blanchecotte-Devilette, Cath Dome, Celdric Duchemin, Eric Hattab, François Hureau, Willy Leclerc, Nadine Lefèvre, Arlaten Leonis, Peter Rothman, Dan Sarle, Laurent Toussaint, and also the journalists in this group who found new documents: Lauren Collins, Marianne Enault, Élodie Pakosz, and Olivier Sibille. I want to thank Leonid Gavrilov and Natalia Gavrilova, who supportively encouraged me to write an article about this research, and Aubrey de Grey for the same reason and his patience. My thanks go also to Robert Young, director of the GRG Supercentenarian Research and Database Division, who had the initiative to constitute a supercentenarian database back in the 1990s, which I used here with his authorization. I thank also for their help Cyrille Vivarelli, archivist of the Beaucaire 
municipal archives, and Claude Mazert and Philippe Regnier, from genealogical associations in the Gard department, and also all the archives and genealogical associations who published online civil registration and other registers. I would like to thank for their comments, corrections, and suggestions on my article: Robert Young, Michel Allard, Jean-Marie Robine, Cyril Depoudent, Edouard Debonneuil about the statistical part, despite disagreements on the wording of corresponding interpretations, Mélanie PernyVilleneuvem and Nikolay Zak. My research started after reading, in the end of 2018, the analysis from Nikolay Zak and Yuri Deigin about the identity swap hypothesis, and I would like to credit them for this, and also, together with Philip Gibbs, for their research, which added motivation to mine although my conclusions are largely opposite. I would like also to apologize to all the people who deserve to be named here and whom I certainly forgot; it was not intentional. Last but not least, I want of course to thank the extraordinary JC, who never refused any test from the researchers and who gave some unforgettable testimonies of her happy, positive, humorous character and of her strong passion for life along all her interviews.

\section{Author Disclosure Statement}

No competing financial interests exist.

\section{Funding Information}

No funding was received for this research.

\section{References}

1. Allard M, Lèbre V, Robine JM. The 120 Years of Jeanne Calment, World's Elder [in French]. Paris: Le ChercheMidi, 1994.

2. Jeune B, Robine JM, Young R, Desjardins B, Skytthe A, Vaupel JW. Jeanne Calment and her successors. Biographical notes on the longest living humans. In: Maier $\mathrm{H}$, Gampe J, Jeune B, Robine JM, Vaupel J (eds): Supercentenarians. Demographic Research Monographs. Berlin \& Heidelberg: Springer, 2010.

3. Gavrilov LA, Gavrilova NS. Validation of exceptional longevity. Book review. Popul Dev Rev 2000;26:40-41.

4. Brouard N. Long term decline of mortality in France, some biases which hide the Gompertz law of mortality and the plateauing of life expectancy. Paris: Presentation at the Paris Seminar in Economic Demography, March 6, 2012.

5. Zak N, Gibbs PE. A bayesian assessment of the longevity of Jeanne Calment. Rejuvenation Res 2020;23:3-16.

6. Human Mortality Database. University of California, Berkeley (USA), and Max Planck Institute for Demographic Research (Germany). www.mortality.org (accessed November 5, 2019).

7. Gerontology Research Group, Table B-Verified Supercentenarians (Ranked By Age) as of January 1st, 2015 (excludes incomplete validated cases). https://grg.org/ Adams/B.HTM (last accessed on December 26, 2019).

8. Robine JM, Allard M, Herrmann FR, Jeune B. The real facts supporting Jeanne Calment as the oldest ever human. J Gerontol A Biol Sci Med Sci 2019. DOI: 10.1093/ gerona/glz198.
9. International Longevity Database (IDL). https://www .supercentenarians.org/ (last accessed November 20, 2019).

10. Official magazine of Kikaï, 2018 (Public Relations, 2018, June 2018). https://www.town.kikai.lg.jp/koho/machi/koho/ documents/kouhou201806.pdf (last accessed on May 3, 2019).

11. "Validated Deceased Supercentenarians (recent deaths 2008 to present in chronological order)" table on the GRG website. http://www.grg.org/Adams/TableE.html (last accessed on November 17, 2019).

12. Robert Young. Personal communication. 2019.

13. Vallin J, Berlinguer G. From endogenous mortality to the maximum human life span. In: Caselli G, Vallin J, Wunsch G (eds): Demography: Analysis and Synthesis. Burlington: Academic Press (Elsevier), 2006, vol. 2, chapter 48.

14. Interview of Nicolas Brouard in: France 2, Envoyé spécial, The Jeanne Calment enigma [in French]. 2019. YouTube. https://youtu.be/Er2sTdYj0Kc (last accessed on November 16, 2019).

15. Robine JM, Allard M. Jeanne Calment: Validation of the duration of her life. In: Jeune B, Vaupels JW (eds): Validation of Exceptional Longevity. Odense: Odense University Press, 1999.

16. Departmental archives of the Bouches-du-Rhône department. AD13. http://www.archives13.fr/

17. Lamy J-C. The Mystery of the Jeanne Calment room [in French]. Paris: Fayard, 2013.

18. Letter of Jeanne Calment to Mrs. André Taque, 18th Aug. 1977. Communicated by Claudie Taque (daughter of the recipient) on the Facebook group "Contre-enquête sur l'enquête Jeanne Calment.” 2019. https://www.facebook.com/groups/ 763398500702857/permalink/811900762519297/ (last accessed on November 16, 2019).

19. Municipal archives of Nimes, Civil registration. http:// www.brozer.fr/telearchives/\#depot_collections.php?d= $1 \& \mathrm{r}=6009 \& \mathrm{c}=10445 \& \mathrm{fn}=234$ (last accessed on December 16, 2019).

20. [Death of Espartero] Mort d'Espartero, article in Le Petit Marseillais. 1896, p. 3. https://www.retronews.fr/journal/ le-petit-marseillais/9-octobre-1896/437/2703759/3

21. Marseille's index, Directory of the Bouches-du-Rhône department [in French] 1841-1980 (editions 1842 to 1981). https://gallica.bnf.fr/ark:/12148/cb32790730k/date .item

22. Facebook group Counter-investigation on the Jeanne Calment investigation [in French]. https://www.facebook .com/groups/763398500702857/ (last accessed on November 16, 2019).

23. Departmental archives of the Bouches-du-Rhône department (AD13), censuses. http://www.archives13.fr/archive/ recherche/recensement $2 / \mathrm{n}: 45$

24. Levraud C. [118 years, prototype of longevity] 118 ans, prototype de longévité. 1993. Doctoral thesis in Medicine, for the diploma in gerontology. 1991/1992 and 1992/1993. Faculty of Medicine of Marseille.

25. Bonnel M. Beyond the 122 years with Jeanne Calment [in French]. 1995. Video, 14 minutes. https://www.canal-u.tv/ video/canal_u_medecine/au_dela_de_120_ans_avec_jeanne_ calment.2782 (last accessed on November 11, 2019).

26. Perny-Villeneuve M, Robin-Champigneul F. CounterInvestigation about Jeanne Calment's longevity, 20th Aug. 2019, comment on the article from Gavrilov L \& Gavrilova N, Late-life mortality is underestimated because of 
data errors. PLoS Biol 2019. DOI: 10.1371/journal.pbio .3000148 .

27. Zak N. Evidence that Jeanne Calment died in 1934, not 1997. Rejuvenation Res 2019;22:3-12.

28. Mahonne. In: CNRTL. https://www.cnrtl.fr/definition/ mahonne (last accessed on November 1, 2019).

29. Épontille. In: CNRTL. https://www.cnrtl.fr/definition/ $\%$ C3\%A9pontille (last accessed on November 1, 2019).

30. Letter of Jeanne Calment to Mrs. André Taque, dated "Friday 29th December 1983." Communicated by Claudie Taque on the Facebook group "Contre-enquête sur l'enquête Jeanne Calment," 23rd Mar. 2019. https://www.facebook.com/ groups/763398500702857/permalink/812752942434079/ (last accessed on April 3, 2019).

31. Arles' birth decennial table for 1883-1892. AD13. http://www.archives13.fr/ark:/40700/vtace99f74368d88dd5/ daogrp/0/32

32. Arles' birth decennial table for 1893-1902. AD13. http://www.archives13.fr/ark:/40700/vtad761cfff1de14ca2/ daogrp/0/31

33. "Recognition and acceptation of use" [in French], notary act from 13th Jan. 1926, with Jeanne and Fernand Calment. Arles, Maître Arnaud's notary office, 1926, folio 105 act 423. AD13, call number "402 E 713." http://www .archives13.fr/

34. Letter of Jeanne Calment to Mrs. Micheline Billot (wife of Robert Billot, nephew of the colonel Billot), 16th Aug. 1957. Communicated by Frédérique Skyronka (daughter of the recipient), posted on her behalf by Cécile Pellegrini on the Facebook group "Contre-enquête sur l'enquête Jeanne Calment," 4th Mar. 2019. https://www.facebook.com/ groups/763398500702857/permalink/801433206899386/ (last accessed on April 3, 2019).

35. Marriage of Marguerite Crouanson \& Marius Deshons, Marseille, 14th Apr. 1898. http://www.archives13.fr/ark:/ 40700/vta8fe5494d5e64ccf7/daogrp/0/13

36. Marriage of Marie Calment \& Louis Vial, Arles, 5th Jun. 1900. http://www.archives13.fr/ark:/40700/vtaaad5864d7c6bf1c7/ daogrp/0/76

37. Identity card of Jeanne Calment dated from 11th January 1930, reproduced in the French magazine VSD from 26th Jan. 1995, article "120 years, the good Lord must have forgotten me" [in French].

38. Jeanne Calment's tax return for the national solidarity tax (ISN), declaration number 1798, dated from 27th July 1946. AD13, call number " 217 W 16." http://www .archives13.fr/

39. Wedding contract between Yvonne Calment and Joseph Billot, 17th January 1926, Maître Arnaud's notary office, 1926, folio 111, act 447. AD13, call number "402 E 713." http://www.archives13.fr/

40. Porlier C, Clergue L. The grandma of the world [in French], article in the French magazine Paris Match, July 1,1988 .

41. Gabriel S. [Jeanne Calment, The Passion to Live] Jeanne Calment, La passion de vivre. Monaco: Editions du Rocher, Jean-Paul Bertrand éditeur, 1995.

42. Image JeanneCalmentaged22.jpg on Wikimedia. https:// commons.wikimedia.org/wiki/File:JeanneCalmentaged22 .jpg (last accessed on November 26, 2019).

43. Zak N. Negligible senescence or life annuity [in Russian], 122-page presentation. https://1drv.ms/b/s!AveUlZgMErh
Bi4sFaLwZLEPw2_yEpg (last accessed on November 26, 2019).

44. Rouquette JM (under the direction of), ARLES. History, territories and cultures [in French]. Arles: Actes Sud, 2008.

45. Le Petit Républicain, journal of the Arles' arrondissement, 27th January 1934 (on microfilm at the Municipal archives of Arles).

46. Yvonne Billot-Calment's death notification ("avis de décès"), Arles media library, Fond Fassin, call number M.2696, January 1934.

47. Tom Méry. Personal communication to Robert Young, quoting his grandmother Gilberte Méry. 2019.

48. Le Pomellec C. Jeanne Calment: Our counter-investigation [in French]. Paris Match, January 24, 2019.

49. Enault M. Her summers with the real Jeanne Calment [in French], (title later changed for "Jeanne Calment: The testimony of her closest relative"). Le Journal du Dimanche, January 27, 2019.

50. Testimony of Claude Chaix to the author, 18th May 2019, published by F. Robin-Champigneul with her authorization on the Facebook group “Contre-enquête sur l'enquête Jeanne Calment" on 19th May 2019. https://www.facebook.com/ groups/763398500702857/permalink/848885122154194/ (last accessed on May 19, 2019).

51. Carrette D. Jeanne Calment's great-niece is 100 years old [in French]. Le Journal de Saône-et-Loire September 23, 2013.

52. Cavalié F. Jeanne Calment, "God's forgotten one" [in French]. Boulogne-Billancourt: TF1 éditions. 1995.

53. Vigneron S. The Identity of the persons, its legal protection [in French]. Doctoral thesis. Paris: Maurice Lavergne, 1937. Chapter 3 (online on Gallica).

54. Friends of the Old Arles' Bulletin [in French] 1986;58:11. http://www.amisduvieilarles.com/assets/files/bulletins/pdf/ 58p.pdf.

55. [Friends of the Old Arles' Bulletin] Bulletins des Amis du Vieil Arles. Arles, 1997;97:50. http://www.amisduvieilarles .com/assets/files/bulletins/pdf/97p.pdf

56. Allard M, Robine JM. The French Centenarians; Study from the IPSEN Foundation 1990-2000 [in French]. collection “L’Année Gérontologique.” Paris: Serdi Edition, 2001.

57. Garoyan G. 114 years of life, or the long story of Jeanne Calment, France's elder [in French]. Doctoral thesis in Medicine, under the direction of Marc Sankalé. Faculty of Medicine of Marseille. 1990.

58. Testimony of Claudine Serena to the author, 6th Nov. 2019.

59. Le Bourg É. Jeanne Calment's daughter usurped her mother's identity-An amateur work or scientific research? [in French]. Med Sci (Paris) 2019;35:375-380.

60. Vallin J, Meslé F. French mortality tables for the 19th and 20th centuries and projections for the 21 st century [in French]. Paris: INED, 2001. (Données statistiques, no. 42001).

61. Theoretical and practical textbook for inheritance declarations [in French]. by the authors of the Registration Journal (Journal de l'enregistrement) and the Notarial jurisprudence folder (Juris-Classeur notarial). Paris, 1935. Chapter XVI pages 15, 42, 43 \& 54. https://gallica.bnf.fr/ ark:/12148/bpt6k5815265s

62. Wedding contract between Jeanne Calment and Fernand Calment, 7th April 1896, Maître Arnaud's notary office, 
1896. AD13, call number “402 E.” http://www.archives13 .fr/

63. Journal officiel de la République française, 1st Feb. 1931, p.1157. https://gallica.bnf.fr/ark:/12148/bpt6k5815265s

64. La Provence, 8th Dec. 1929, p. 3. Bibliothèque nationale de France (National Library of France, in Paris). Microfilm, call number "MFILM JO-88570.",

65. Le Petit Marseillais, 12th Feb. 1907, p.2. https://www .retronews.fr/journal/le-petit-marseillais/12-fevrier-1907/437/ 2658413/2

66. Pearl R, DeWitt Pearl R. Studies on human longevity VI. The distribution and correlation of variation in the total immediate ancestral longevity of nonagenarians and centenarians, in relation to the inheritance factor in duration of life. Hum Biol 1934;6:98-222.

67. Le Page A, Depoudent C. Longevity and population [in French]. blog article. 2018. http://centenaires-francais .forumactif.org/t119p25-longevite-et-population\#6684 (last accessed on October 19, 2019).

68. Le Page A, Depoudent C. Hereditary part in Jeanne Calment's longevity [in French]. blog article. 2018. http:// centenaires-francais.forumactif.org/t115-c-biographie-dejeanne-calment-1875-1997\#6738 (last accessed on October 19, 2019).

69. Blayo Y. Natural movement of the French population from 1740 to 1829 [in French]. Population 1975;30:15-64.

70. Schofield R. Short-run and secular demographic response to fluctuations in the standard of living in England, 1540-1834. In: Bengtsson T, Saito O (eds), Population and Economy: From Hunger to Modern Economic Growth. New York: Oxford University Press, 2000, pp. 49-71.

71. Van Poppel F, Bijwaard G, Van Lieburg M, Van Lieburg F, Hoekstra R, Verkade F. The life expectancy of medical professionals in the Netherlands, sixteenth to twentieth centuries. Population 2016;71:619-640.

72. Fornasin A, Breschi M, Manfredini M. Mortality patterns of cardinals (sixteenth-twentieth centuries). Population 2010;65:631-652.

73. Robine JM, Allard M. The oldest human. Science 1998; 279:1834-1835.

74. Kaptijn R, Thomese F, Liefbroer AC, Van Poppel F, Van Bodegom D, Westendorp RG. The trade-off between female fertility and longevity during the epidemiological transition in the Netherlands. PLoS One 2015;10:e0144353.

75. Ancestry of King George V (1865-1936). http://roglo.eu/ roglo?lang $=\mathrm{fr} ; \mathrm{m}=\mathrm{A} ; \mathrm{p}=$ george $; \mathrm{n}=$ windsor $; \mathrm{oc}=5 ; \mathrm{sosab}=10$; $\mathrm{t}=\mathrm{Z}$; birth=on;birth_place=on;marr=on;marr_date=on;marr_ place $=$ on;death $=$ on;death_place $=$ on;death_age $=o n ; o c c u=o n$; gen $=\mathrm{on} ;$ repeat $=\mathrm{on} ; \mathrm{bd}=0 ;$ color $=; \mathrm{evt}=\mathrm{on} ; \mathrm{v}=6$ (last accessed on December 23, 2019)

76. Sri Kantha S. Total immediate ancestral longevity (TIAL) score as a longevity indicator: an analysis on Einstein and three of his scientist peers. Med Hypotheses 2001;56:519522.

77. Desjardins B. Is longevity inherited? A comparison of the ancestors of two of the world's oldest inhabitants. Popul English Sel Biodemographic Perspect Hum Longevity. 2001;13:237-241.

78. Gavrilov LA, Gavrilova NS. Predictors of exceptional longevity: effects of early-life childhood conditions, midlife environment and parental characteristics. Living 100 Monogr 2014;2014:1-18.
79. Lacour-Gayet J. History of Trade, volume 4. In: Trade from the 14th century to the middle of the 19th century [in French]. Paris: Spid, 1951.

80. [Friends of the Old Arles' Bulletin] Bulletin des Amis du Vieil Arles. Arles, 1976;23:13. http://www.amisduvieilarles .com/assets/files/bulletins/pdf/23p.pdf

81. Allard M. Happiness has no age [in French]. Paris: Cherche midi, 2019.

82. Johannes F. Arles offers a farewell Mass to Jeanne Calment [in French]. August 8, 1997.

83. Jeanne Calment, 113 years, oldest of the French [in French]. Le Monde, December 9, 1988.

84. Chen L, Zhu H, Gutin B, Sesso HD, Dong Y. Higher chocolate intake is associated with longer telomere length among adolescents. Pediatr Res 2019. DOI: 10.1038/s41390-0190590-6.

85. "Life expectancy by age and sex" in 1997, Eurostat. https:// appsso.eurostat.ec.europa.eu/nui/show.do?query=BOOK MARK_DS-051880_QID_-2A5D8E55_UID_-3F171EB0\& layout=SEX,L,X,0;GEO,L,Y,0;TIME,C,Z,0;AGE,L,Z,1; UNIT,L,Z,2;INDICATORS,C,Z,3;\&zSelection=DS-051880 UNIT,YR;DS-051880TIME,1997;DS-051880AGE,Y80;DS051880INDICATORS,OBS_FLAG;\&rankName1=UNIT_ 1_2_-1_2\&rankName2=AGE_1_2_-1_2\&rankName3= INDICATORS_1_2_-1_2\&rankName4=TIME_1_0_0_1\& rankName5=SEX_1_2_0_0\&rankName6=GEO_1_2_0_ $1 \&$ sortR $=$ ASC_2\&rStp $=\& \mathrm{cStp}=\& \mathrm{rDCh}=\& \mathrm{cDCh}=\& \mathrm{rDM}=$ true $\& \mathrm{cDM}=$ true $\&$ footnes $=$ false $\&$ empty $=$ false $\&$ wai $=$ false \&time_mode $=$ NONE\&time_most_recent $=$ false $\&$ lang $=E N \&$ $\mathrm{cfo}=\% 23 \% 23 \% 23 \% 2 \mathrm{C} \% 23 \% 23 \% 23 . \% 23 \% 23 \% 23$ (last accessed on October 31, 2019).

86. Population by sex and quinquennial age from 1968 to 2015, harmonized censuses-Departmental and communal series [in French]. INSEE. 2018. https://www.insee.fr/ fr/statistiques/1893204 (last accessed on November 3, 2019).

87. Cournil A, Robine JM, Allard M. Validation of a protocol for the collection of longitudinal survival data in Arles (France). In: Jeune B, Vaupels JW (eds): Validation of Exceptional Longevity. Odense: Odense University Press, 1999.

88. Temperatures records for Nîmes. Infoclimat. https://www .infoclimat.fr/climatologie/globale/mois-de-janvier/nimescourbessac/07645.html\#stats-mois-details (last accessed on October 30, 2019).

89. Meteo France. History of the January 1985 's cold wave [in French]. January 9, 2015. http://www.meteofrance.fr/ actualites/20767002-retour-sur-la-vague-de-froid-de-janvier1985 (last accessed on October 30, 2019).

90. Mourtzoukou EG, Falagas ME. Exposure to cold and respiratory tract infections. Int J Tuberc Lung Dis 2007;11: 938-943.

91. Keil G, Cummings E, de Magalhães JP. Being cool: how body temperature influences ageing and longevity. Biogerontology 2015;16:383-397.

92. Kang BS, Song SH, Suh CS, Hong SK. Changes in body temperature and basal metabolic rate of the ama. J Appl Physiol 1963;18:483-488.

93. Castaldo L, Narváez A, Izzo L, et al. Red wine consumption and cardiovascular health. Molecules 2019;24: pii: E3626.

94. Herzberg N, Mandraud I, Aubenas F. Has Jeanne Calment been 122 years old? Investigation about the wild hy- 
pothesis from two Russian researchers [in French]. Le Monde, February 14, 2019.

95. Holstege H, Pfeiffer W, Sie D, et al. Somatic mutations found in the healthy blood compartment of a 115-yr-old woman demonstrate oligoclonal hematopoiesis. Genome Res 2014;24:733-742.

96. Lancaster FM. Genetic and quantitative aspects of genealogy. http://www.genetic-genealogy.co.uk/Toc115570157 .html\#Coefficient_inbreeding (last accessed on September 29, 2019).

97. Leutenegger AL, Prum B, Genin E, et al. Estimation of the inbreeding coefficient through use of genomic data. Am J Hum Genet 2003;73:516-523.

98. Polašek O, Hayward C, Bellenguez C, et al. Comparative assessment of methods for estimating individual genomewide homozygosity-by-descent from human genomic data. BMC Genomics 2010;11:139.

99. Leutenegger AL, Sahbatou M, Gazal S, Cann H, Génin E. Consanguinity around the world: what do the genomic data of the HGDP-CEPH diversity panel tell us? Eur J Hum Genet 2011;19:583-587.

100. Chambre D, Jeune B, Poulain M. Geert Adriaans Boomgaard, the first supercentenarian in history? 2018, Archives from Groningen. https://www.groningerarchieven .nl/images/blog/2018-BOOMGAARD-Chambre-JeunePoulain.pdf (last accessed on May 28, 2019).

101. World Health Organization. World Health Statistics 2018 (data for 2016). https://www.who.int/gho/publications/ world_health_statistics/2018/en/ (last accessed on December 23, 2019).

102. Institut Monégasque de la Statistique et des Études Économiques (IMSEE), Monaco Statistics, Observatoire de la Démographie. https://www.imsee.mc/Population-etemploi/Demographie (last accessed on December 23, 2019).

103. Figures from the Japanese Ministry of Health, Labor and Welfare. https://www.nippon.com/en/features/h00250/ life-expectancy-for-japanese-men-and-women-at-newrecord-high.html (last accessed on January 11, 2020).

104. 4,600 increase in number of China's centenarians. Shanghai Daily, October 22, 2014. http://www.china.org .cn/china/2014-10/22/content_33834793.htm (last accessed on January 11, 2020).

Address correspondence to: François Robin-Champigneul Independent Scholar 16 rue de l'Avre Paris 75015

France

E-mail: frachamp@gmail.com

Received: December 25, 2019 Accepted: January 11, 2020 


\section{Appendix}

\section{Appendix A1: Mortality Models}

The mortality models used are defined with their formula and parameters, as established by Robine et al., ${ }^{8}$ except for the L-Avg model (Table A1), which is introduced here:

Logistic models: $q_{x}$ (age $)=b_{0}+b_{1} /\left(1+\exp \left(-b_{2} \times(\right.\right.$ age $\left.\left.b_{3}\right)\right)$ )

L-1903: $\quad b_{0}=0.0062, \quad b_{1}=0.6403, \quad b_{2}=0.1241$, $b_{3}=99.7883$.
L-1875: $\quad b_{0}=0.0071, \quad b_{1}=0.6819, \quad b_{2}=0.1078$, $b_{3}=97.8033$.

L-Avg: $\quad b_{0}=0.00665, \quad b_{1}=0.6611, \quad b_{2}=0.11595$, $b_{3}=98.7958$.

Gompertz models: $q_{x}($ age $)=b_{0}+b_{1} \times \exp \left(-\exp \left(-b_{2} \times\right.\right.$ $\left(\right.$ age $\left.\left.-b_{3}\right)\right)$ )

G-1903: $\quad b_{0}=0.0138, \quad b_{1}=1.1814, \quad b_{2}=0.0463$, $b_{3}=106.1697$.

G-1875: $\quad b_{0}=0.016, \quad b_{1}=1.4365, \quad b_{2}=0.0379$, $b_{3}=108.0642$.

Appendix Table A1. L-Avg Model Mortality Table for the G7 Countries' 1850-1900 Birth Cohort

\begin{tabular}{|c|c|c|c|c|c|c|c|}
\hline \multirow[b]{2}{*}{ Age } & \multirow[b]{2}{*}{$\begin{array}{l}\text { Mortality } \\
\text { quotient } \\
\left(\mathrm{q}_{\mathrm{x}}\right), \%\end{array}$} & \multirow[b]{2}{*}{$\begin{array}{l}\text { Population } \mathrm{l}_{\mathrm{x}} \\
\text { (expected value } \\
\text { of } \mathrm{N}_{\mathrm{x}} \text { ) }\end{array}$} & \multicolumn{5}{|c|}{ Survival probabilities } \\
\hline & & & $\begin{array}{c}\text { Individual } \\
\text { survival probability } \\
\left(=\mathrm{l}_{\mathrm{x}} / \mathrm{N}_{100}\right)\end{array}$ & $\begin{array}{c}\text { No one } \\
\text { surviving } \\
\mathrm{P}\left(\mathrm{N}_{\mathrm{x}}=0\right), \%\end{array}$ & $\begin{array}{c}\text { At least } \\
\text { one surving } \\
\mathrm{P}\left(\mathrm{N}_{\mathrm{x}} \geq 1\right), \%\end{array}$ & $\begin{array}{c}\text { Exactly } \\
\text { one surving } \\
\mathrm{P}\left(\mathrm{N}_{\mathrm{x}}=1\right), \%\end{array}$ & $\begin{array}{c}\mathrm{P} \text { (oldest } \\
\text { age), \% }\end{array}$ \\
\hline 100 & 36.02 & $566,945.83$ & $100 \%$ & 0 & 100 & 0 & 0.00 \\
\hline 101 & 37.92 & $362,709.59$ & $63.98 \%$ & 0.00 & 100.00 & 0.00 & 0.00 \\
\hline 102 & 39.79 & $225,165.74$ & $39.72 \%$ & 0.00 & 100.00 & 0.00 & 0.00 \\
\hline 103 & 41.62 & $135,570.62$ & $23.91 \%$ & 0.00 & 100.00 & 0.00 & 0.00 \\
\hline 104 & 43.40 & $79,144.87$ & $13.96 \%$ & 0.00 & 100.00 & 0.00 & 0.00 \\
\hline 105 & 45.12 & $44,795.09$ & $7.90 \%$ & 0.00 & 100.00 & 0.00 & 0.00 \\
\hline 106 & 46.78 & $24,582.66$ & $4.34 \%$ & 0.00 & 100.00 & 0.00 & 0.00 \\
\hline 107 & 48.35 & $13,084.02$ & $2.31 \%$ & 0.00 & 100.00 & 0.00 & 0.00 \\
\hline 108 & 49.86 & 6757.25 & $1.19 \%$ & 0.00 & 100.00 & 0.00 & 0.00 \\
\hline 109 & 51.27 & 3388.40 & $0.60 \%$ & 0.00 & 100.00 & 0.00 & 0.00 \\
\hline 110 & 52.61 & 1651.05 & $0.29 \%$ & 0.00 & 100.00 & 0.00 & 0.00 \\
\hline 111 & 53.85 & 782.48 & $0.14 \%$ & 0.00 & 100.00 & 0.00 & 0.00 \\
\hline 112 & 55.02 & 361.08 & $0.06 \%$ & 0.00 & 100.00 & 0.00 & 0.00 \\
\hline 113 & 56.10 & 162.42 & $0.03 \%$ & 0.00 & 100.00 & 0.00 & 0.00 \\
\hline 114 & 57.09 & 71.31 & $0.01 \%$ & 0.00 & 100.00 & 0.00 & 0.00 \\
\hline 115 & 58.01 & 30.59 & $0.01 \%$ & 0.00 & 100.00 & 0.00 & 0.00 \\
\hline 116 & 58.86 & 12.85 & $2.3 \mathrm{E}-05$ & 0.00 & 100.00 & 0.00 & 0.51 \\
\hline 117 & 59.63 & 5.28 & 9.3E-06 & 0.51 & 99.49 & 2.68 & 11.34 \\
\hline 118 & 60.34 & 2.13 & $3.8 \mathrm{E}-06$ & 11.84 & 88.16 & 25.27 & 31.06 \\
\hline 119 & 60.98 & 0.85 & $1.5 \mathrm{E}-06$ & 42.91 & 57.09 & 36.31 & 28.97 \\
\hline 120 & 61.56 & 0.33 & $5.8 \mathrm{E}-07$ & 71.88 & 28.12 & 23.73 & 16.20 \\
\hline 121 & 62.09 & 0.13 & $2.2 \mathrm{E}-07$ & 88.08 & 11.92 & 11.18 & 7.22 \\
\hline 122 & 62.57 & 0.05 & 8.5E-08 & 95.30 & 4.70 & 4.58 & 2.91 \\
\hline 123 & 63.01 & 0.02 & $3.2 \mathrm{E}-08$ & 98.22 & 1.78 & 1.77 & 1.12 \\
\hline 124 & 63.40 & 0.01 & $1.2 \mathrm{E}-08$ & 99.34 & 0.66 & 0.66 & 0.42 \\
\hline 125 & 63.75 & 0.00 & 4.3E-09 & 99.76 & 0.24 & 0.24 & 0.16 \\
\hline
\end{tabular}

Light gray indicates observed ages of the three verified oldest-lived individuals.

Bold indicates the probability of having an age record such as JC's in the cohort.

\section{Appendix A2: Ancestors List}

The ancestors list in Table A2 includes Jeanne and François Calment and their 62 ancestors of five generations. The first column is the Sosa number. Dates are given in
DD/MM/YYYY format. All places are in France in the Bouches-du-Rhône department unless another department is mentioned. The paternal ancestors are with dark gray shading and the maternal ones with light gray shading. 

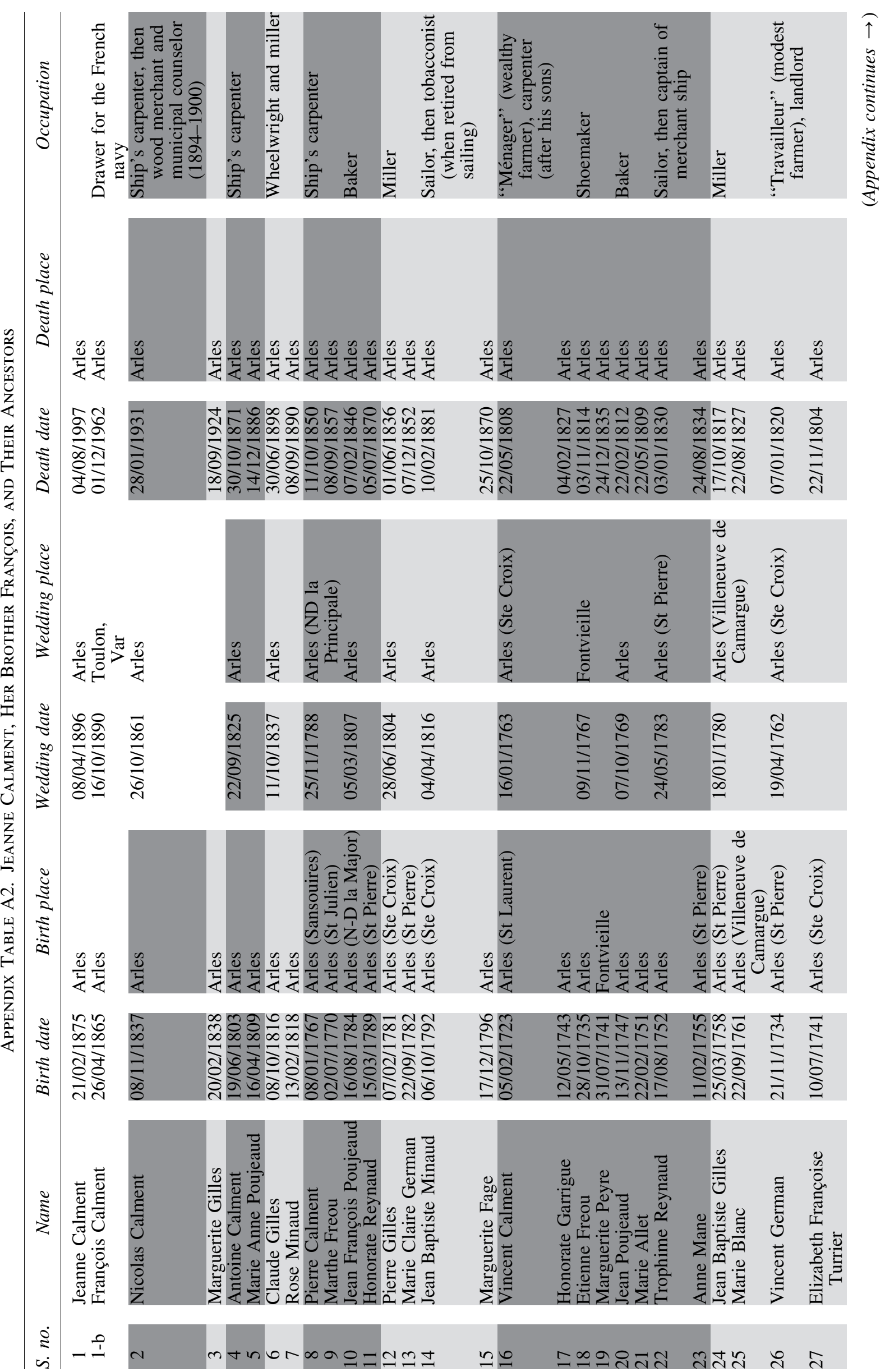


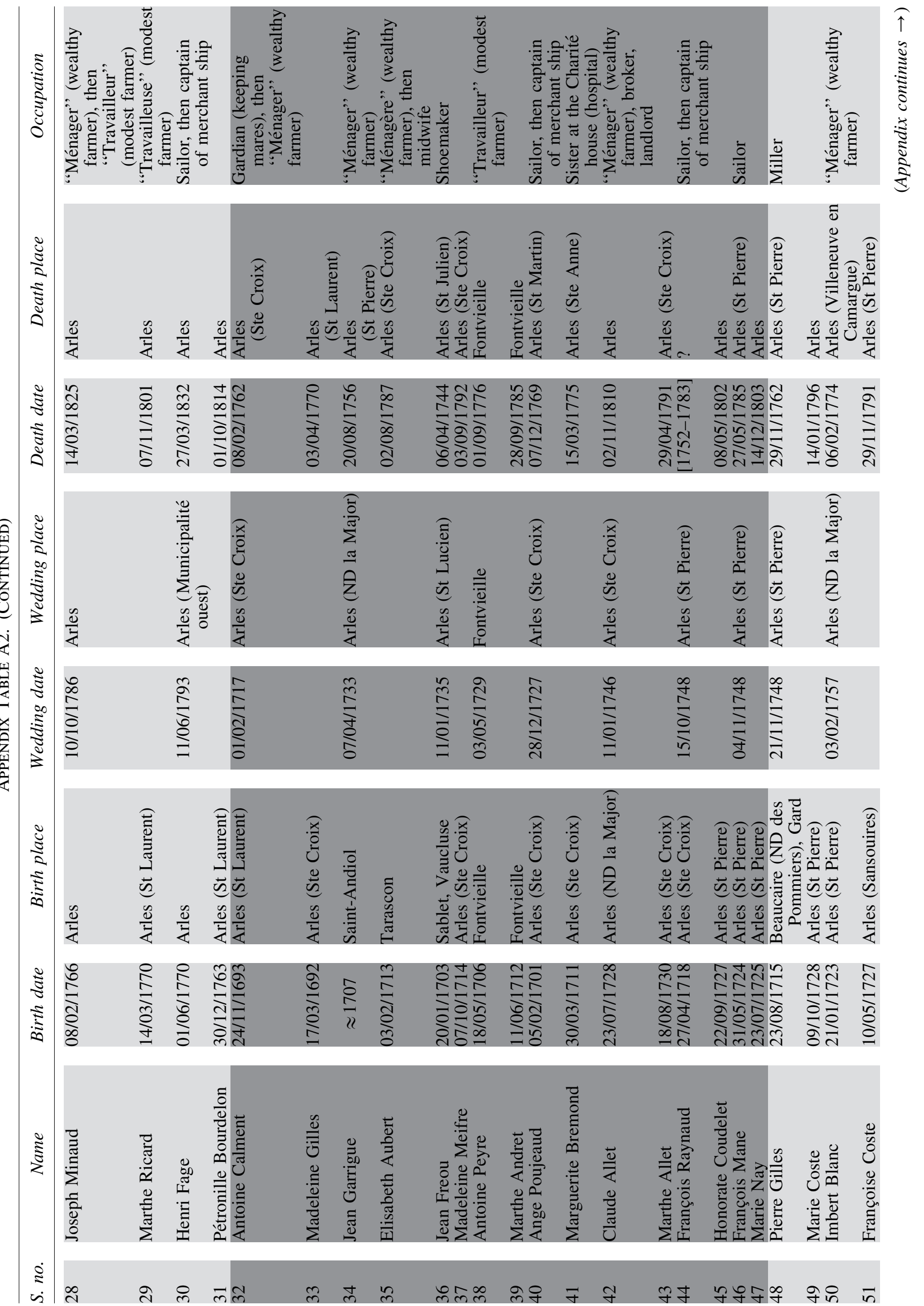




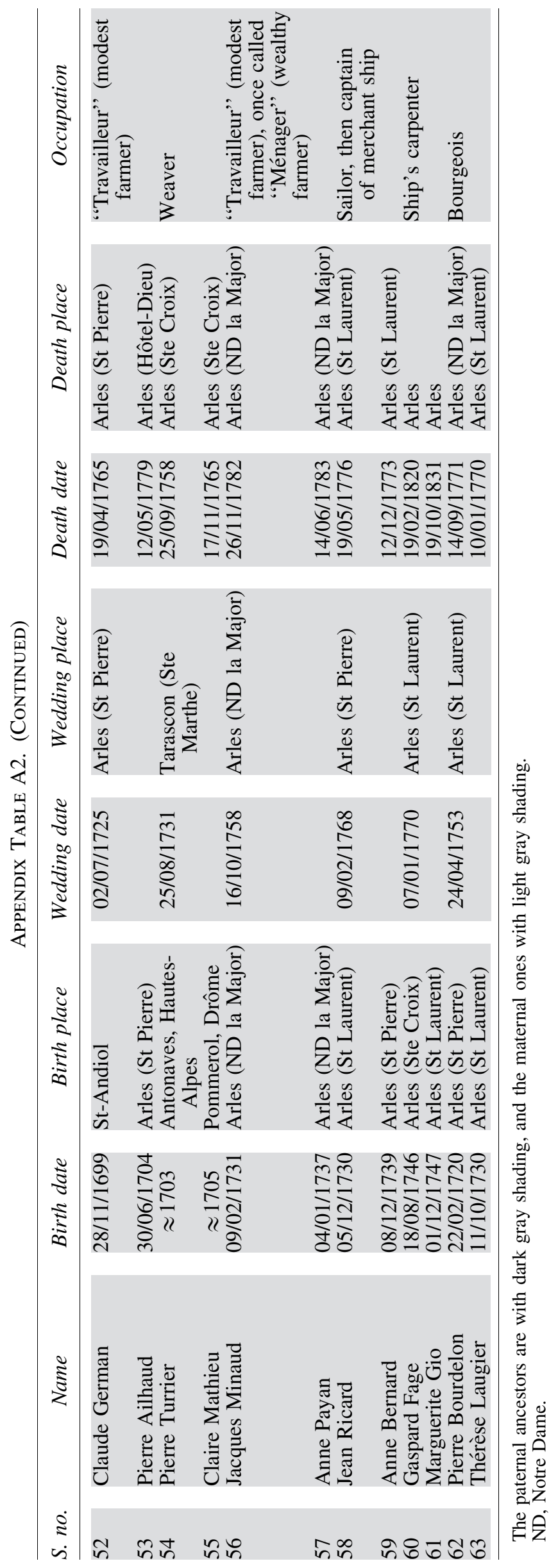

